Report on Carcinogens

MONOGRAPH ON
HELICOBACTER PYLORI
(CHRONIC INFECTION)

ROC MONOGRAPH 14

OCTOBER 2018 


\section{Report on Carcinogens Monograph on Helicobacter pylori (Chronic Infection)}

RoC Monograph 14

October 2018

National Toxicology Program

Public Health Service

U.S. Department of Health and Human Services ISSN: 2331-267X

Research Triangle Park, North Carolina, USA 


\section{Foreword}

The National Toxicology Program (NTP), established in 1978, is an interagency program within the Public Health Service of the U.S. Department of Health and Human Services. Its activities are executed through a partnership of the National Institute for Occupational Safety and Health (part of the Centers for Disease Control and Prevention), the Food and Drug Administration (primarily at the National Center for Toxicological Research), and the National Institute of Environmental Health Sciences (part of the National Institutes of Health), where the program is administratively located. NTP offers a unique venue for the testing, research, and analysis of agents of concern to identify toxic and biological effects, provide information that strengthens the science base, and inform decisions by health regulatory and research agencies to safeguard public health. NTP also works to develop and apply new and improved methods and approaches that advance toxicology and better assess health effects from environmental exposures.

The Report on Carcinogens Monograph series began in 2012. Report on Carcinogens Monographs present the cancer hazard evaluations of environmental agents, substances, mixtures, or exposure circumstances (collectively referred to as "substances") under review for the Report on Carcinogens. The Report on Carcinogens is a congressionally mandated, sciencebased, public health document that provides a cumulative list of substances that pose a cancer hazard for people in the United States. Substances are reviewed for the Report on Carcinogens to (1) be a new listing, (2) reclassify the current listing status, or (3) be removed.

NTP evaluates cancer hazards by following a multistep process and using established criteria to review and integrate the scientific evidence from published human, experimental animal, and mechanistic studies. General instructions for the systematic review and evidence integration methods used in these evaluations are provided in the Handbook for the Preparation of Report on Carcinogens Monographs. The handbook's instructions are applied to a specific evaluation via a written protocol. The evaluation's approach as outlined in the protocol is guided by the nature, extent, and complexity of the published scientific information and tailored to address the key scientific issues and questions for determining whether the substance is a potential cancer hazard and should be listed in the Report on Carcinogens. Draft monographs undergo external peer review before they are finalized and published.

The Report on Carcinogens Monographs are available free of charge on the NTP website and cataloged in PubMed, a free resource developed and maintained by the National Library of Medicine (part of the National Institutes of Health). Data for these evaluations are included in the Health Assessment and Workspace Collaborative. Information about the Report on Carcinogens is also available on the NTP website.

For questions about the monographs, please email NTP or call 984-287-3211. 


\section{Table of Contents}

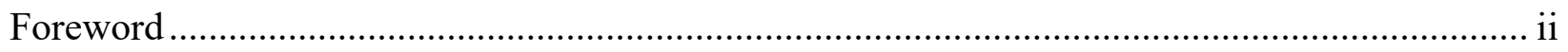

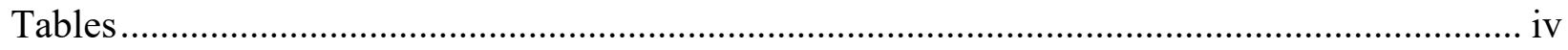

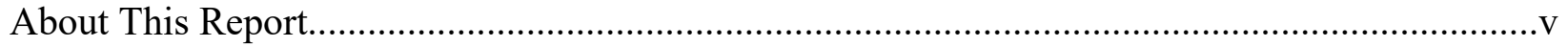

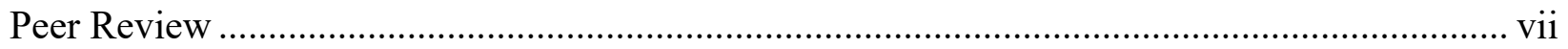

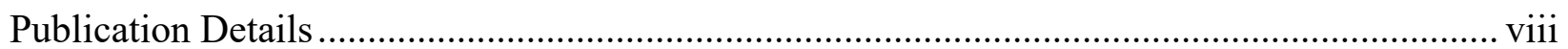

Acknowledgments............................................................................................................. vii

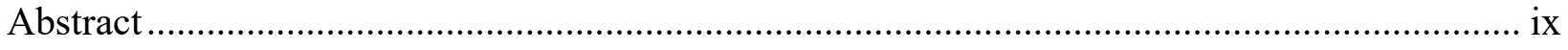

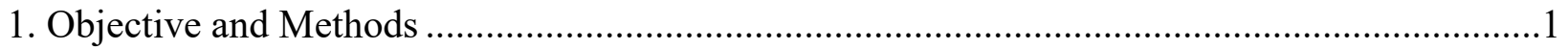

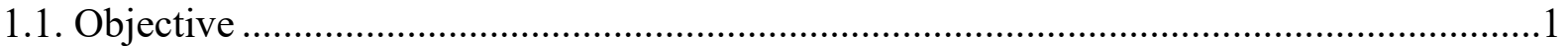

1.2. Monograph Development and Contents.........................................................................

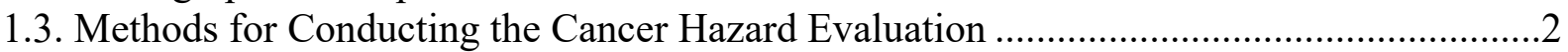

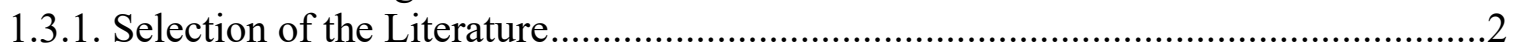

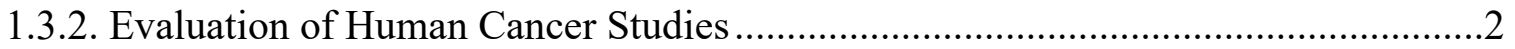

1.3.3. Evaluation of Cancer Studies in Experimental Animals............................................. 3

1.3.4. Evaluation of Mechanistic and Other Relevant Data...............................................

1.3.5. Overall Evaluation and Listing Recommendation..................................................... 3

1.4. Method for Developing the Section on Prevention of H. pylori-associated Cancer.............4

2. Helicobacter pylori (Chronic Infection) Substance Profile ..........................................................

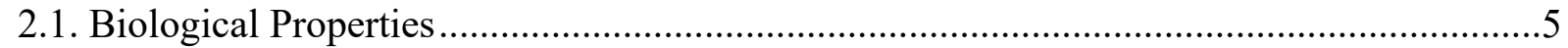

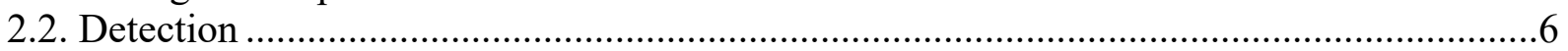

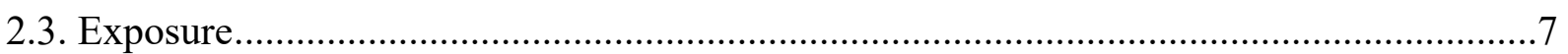

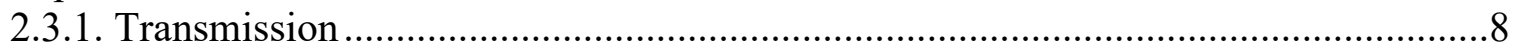

2.3.2. Diseases (Noncancer), Treatment, and Prevention ................................................... 9

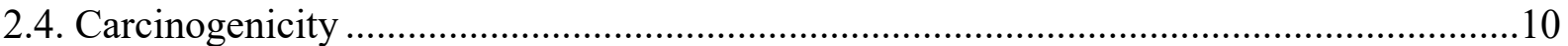

2.4.1. Cancer Studies in Humans ................................................................................ 10

2.4.2. Cancer Studies in Experimental Animals .........................................................12

2.4.3. Mechanisms of Carcinogenesis and Other Relevant Data .......................................12

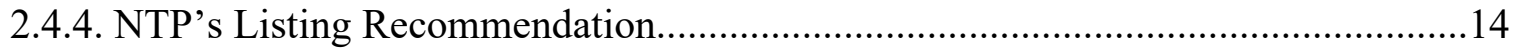

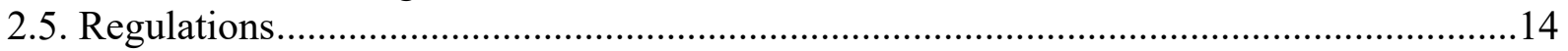

2.5.1. Department of Transportation (DOT) ……......................................................... 14

2.5.2. Food and Drug Administration (FDA, an Agency of Health and Human

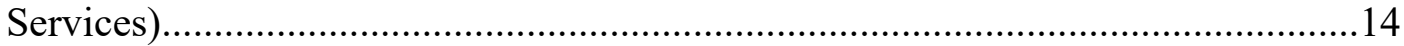

2.5.3. Occupational Safety and Health Administration (OSHA) .......................................14

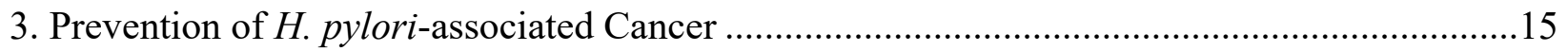

3.1. Prevention of H. pylori-induced Cancers: State of the Science .........................................15

3.1.1. Screening for and Treatment of $H$. pylori Infection ...............................................16

3.1.2. Efficacy and Effectiveness of $H$. pylori Eradication in Preventing Stomach

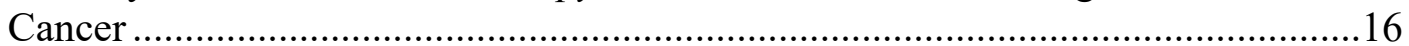

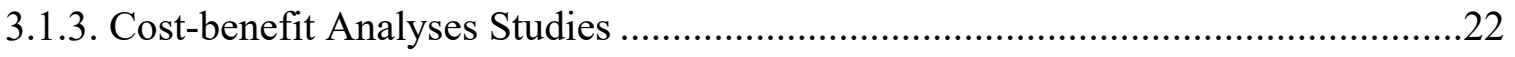

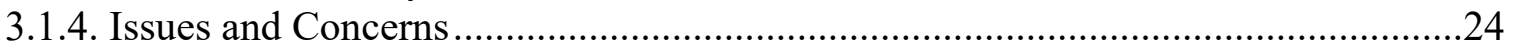




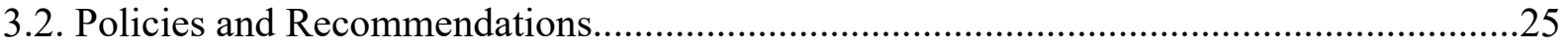

3.2.1. National Consensus Recommendations for the Prevention of H. pylori-

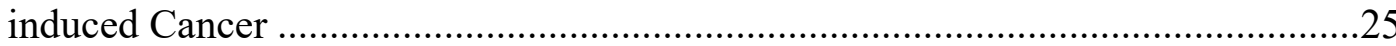

3.2.2. Screening and Treatment Programs ......................................................................2

3.3. Summary of the Recommendations of International Expert Working Groups

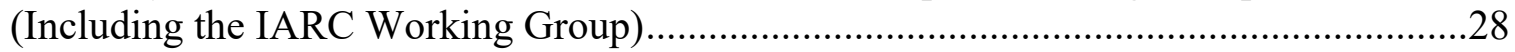

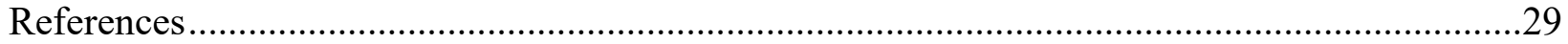

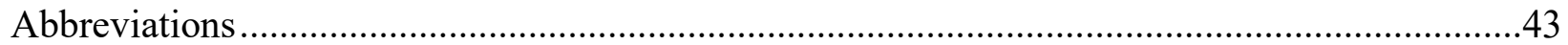

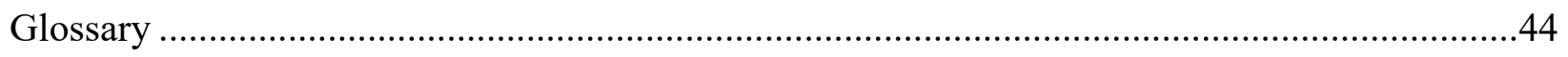

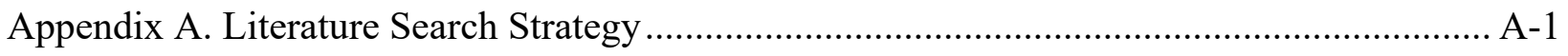

Appendix B. Summary of Human Studies of Pancreatic and Colorectal Cancer ..........................

\section{Tables}

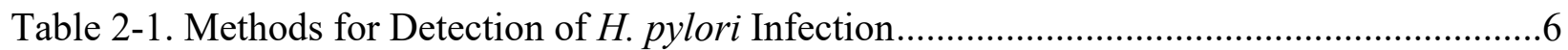

Table 3-1. Randomized Controlled Trials of H. pylori Eradication and the Incidence of

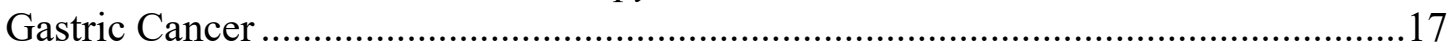

Table 3-2. Meta-analyses of Randomized Controlled Trials and Cohort Studies Investigating the Effectiveness of H. pylori Eradication in Reducing Gastric

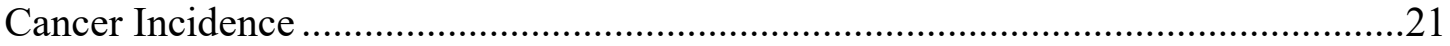

Table 3-3. Recommendations for Prevention of H. pylori-induced Cancer ...................................26

This report has been reformatted to meet new NTP publishing requirements; its content has not changed. 


\section{About This Report}

National Toxicology Program ${ }^{1}$

${ }^{1}$ Division of the National Toxicology Program, National Institute of Environmental Health

Sciences, Research Triangle Park, North Carolina, USA

\section{Collaborators}

Ruth M. Lunn, Whitney Arroyave

Division of the National Toxicology Program, National Institute of Environmental Health Sciences, Research Triangle Park, North Carolina, USA

Executed and coordinated project activities, including conception, design, planning, conduct, or technical review of cancer hazard evaluation

Ruth M. Lunn, Dr.P.H., Project Co-lead

ILS, Inc., Research Triangle Park, North Carolina, USA

Executed and coordinated project activities, including conception, design, planning, conduct, or technical review of cancer hazard evaluation

Whitney Arroyave, Ph.D., Project Co-lead

\section{Contributors}

\section{RoC Internal Review Group}

Provided critical scientific review of the draft monograph prior to external peer review and public release

John Bucher, Ph.D., Chair, DNTP, NIEHS

Brandy Beverly, Ph.D., DNTP, NIEHS

Michelle Hooth, Ph.D., DNTP, NIEHS

David Malarkey, Ph.D., DNTP, NIEHS

Scott M. Masten, Ph.D., DNTP, NIEHS

Suril Mehta, M.P.H., DNTP, NIEHS

Charles Rabkin, M.D., Division of Cancer Epidemiology and Genetics, National Cancer

Institute, Rockville, Maryland, USA

Amy Wang, Ph.D., DNTP, NIEHS

Division of the National Toxicology Program, National Institute of Environmental Health Sciences, Research Triangle Park, North Carolina, USA

Provided technical assistance with the monograph preparation

Gloria Jahnke, D.V.M., DABT

Organized the peer review meeting

Elizabeth A. Maull, Ph.D.

Mary S. Wolfe, Ph.D. 
ILS, Inc., Research Triangle Park, North Carolina, USA

Provided technical assistance with the monograph preparation

Andrew Ewens, Ph.D.

Sanford Garner, Ph.D.

Lara Handler, M.S.L.S.

Alton Peters, M.S.

Provided administrative assistance

Ella J. Darden, B.S.

Tracy L. Saunders, B.S.

Conducted literature searches

Jessica A. Geter, M.S.L.S.

ICF International, Inc., Durham, North Carolina, USA

Provided editorial assistance

Susan Dakin, Ph.D.

Provided logistical support for the peer review meeting

Canden Byrd, B.S.

Kelly Shipkowski, Ph.D. 


\section{Peer Review}

The Draft Report on Carcinogens Monograph on Helicobacter pylori (chronic infection) was peer reviewed by letter by individuals with expertise in $H$. pylori and cancer. The reviewers served as independent scientists and not as representatives of any institution, company, or governmental agency.

The peer reviewers were charged to:

1) Comment on whether the draft monograph was technically correct, clearly stated, and objectively presented.

2) Provide opinion on whether there is currently or was in the past significant human exposure to $H$. pylori.

Each peer reviewer independently was asked to provide opinion on:

1) Whether the scientific evidence supported the NTP's preliminary conclusion on the level of evidence for carcinogenicity from cancer studies in humans.

2) Whether the scientific evidence supported the NTP's preliminary policy decision on H. pylori for listing in the Report on Carcinogens.

The monograph was revised based on NTP's consideration of the peer-review comments.

\section{Peer Reviewers}

\section{Rolando Herrero, M.D., Ph.D.}

Head

Prevention and Implementation Group

Early Detection and Prevention Section

International Agency for Research on Cancer

Lyon, France

Julie Parsonnet, M.D.

George DeForest Barnett Professor in Medicine

Professor of Medicine

Professor of Health Research and Policy

Division of Infectious Diseases and Geographic Medicine

Division of Epidemiology

Stanford University Medical Center

Stanford, California, USA

Traci L. Testerman, Ph.D.

Assistant Professor

Department of Pathology, Microbiology, and Immunology

University of South Carolina School of Medicine

Columbia, South Carolina, USA 


\section{Publication Details}

Publisher: National Toxicology Program

Publishing Location: Research Triangle Park, NC

ISSN: 2331-267X

DOI: https://doi.org/10.22427/ROC-MGRAPH-14

Report Series: RoC Monograph Series

Report Series Number: 14

Official citation: National Toxicology Program (NTP). 2018. Report on Carcinogens monograph on Helicobacter pylori (chronic infection). Research Triangle Park, NC: National Toxicology Program. RoC Monograph 14.

\section{Acknowledgments}

This work was supported by the Intramural Research Program (ES103316 and ES103317) at the National Institute of Environmental Health Sciences, National Institutes of Health and performed for the National Toxicology Program, Public Health Service, U.S. Department of Health and Human Services under contract GS00Q14OADU417 (Order No. HHSN273201600015U). 


\begin{abstract}
Helicobacter pylori is a gram-negative, multi-flagellated bacterium that colonizes the stomach and causes peptic ulcers. More than half the world's population is infected with $H$. pylori with the highest prevalence rates in low- and middle-income countries. The bacterium is spread via person-to-person contact, especially among people of lower socioeconomic status living in crowded conditions and often with poor sanitation. Several international health working groups have linked $H$. pylori with an increased risk of gastric cancer. Because of these public health concerns, the National Toxicology Program (NTP) conducted a literature-based cancer hazard assessment of $H$. pylori and recommended that $H$. pylori be listed as a known human carcinogen in the Report on Carcinogens (RoC), a U.S. Congress-mandated document that provides information on cancer hazards for people residing in the United States. The RoC monograph on H. pylori provides a concise review of the evidence from cancer studies in humans and experimental animals, as well as information on human exposure to H. pylori. As $H$. pylori is thought to account for $6.2 \%$ of all cancer deaths in the world, primarily due to non-cardia gastric cancer, the monograph also provides a summary of the state of the science for prevention of $H$. pylori-induced cancer, including a review of the effectiveness of intervention studies, costbenefit analyses, international working group recommendations, and issues and concerns related to programs that would screen people for $H$. pylori infection and treat those who are infected with antibiotics.
\end{abstract}




\section{Objective and Methods}

\subsection{Objective}

Helicobacter pylori is a gram-negative, multi-flagellated bacterium that colonizes the luminal mucosal surface of the body (corpus) and lower portion (antrum) of the stomach; if untreated, the infection usually lasts for the individual's lifetime. Chronic infection can cause gastritis and peptic ulcers.

The objective of this monograph is to present NTP's conclusions regarding the level of evidence for carcinogenicity from studies in humans and experimental animals and its Report on Carcinogens (RoC) listing recommendation. These conclusions were reached by applying the RoC listing criteria to the cancer assessment.

The rationale for selecting $H$. pylori for review for the RoC and the approach to preparing the monograph were outlined in the draft concept document, "Helicobacter pylori: Chronic Infection" (NTP 2016). The draft concept document was released for public comment and presented to the NTP Board of Scientific Counselors at its meeting on April 11, 2016, which provided opportunity for written and oral public comments. After the meeting, the concept document was finalized, and H. pylori was approved by the NTP Director as a candidate substance for review. The concept document is available on the RoC website (NTP 2016).

\subsection{Monograph Development and Contents}

In developing the monograph, NTP relied on the International Agency for Research on Cancer assessment (IARC 2012) and peer review of the cancer studies in humans and experimental animals and mechanistic and other relevant data. The rationale for relying primarily upon the IARC monograph is that the role of $H$. pylori as the major risk factor for stomach cancer is well established in the scientific community [see the concept document, NTP (2016)].

H. pylori infection is responsible for approximately 780,000 cancer cases annually worldwide (Plummer et al. 2015). The current question for the health community is not about causation, but whether $H$. pylori screening and eradication programs should be implemented and, if so, how these prevention strategies should be carried out. Therefore, this monograph also reports on the status of activities for preventing $H$. pylori-induced stomach cancer. Providing information on activities to reduce exposure is consistent with the spirit of the congressional mandate for the $\mathrm{RoC}$ (as the report is expected to discuss Federal agency regulations to limit exposure) and should facilitate hazard communication efforts when the RoC monograph is published.

The monograph consists of the following sections:

- Objective and methods (Section 1), including methods for conducting the cancer hazard evaluation (Section 1.3)

- Substance profile: Science supporting the listing recommendation (Section 2)

- Status and summary of cancer prevention strategies (Section 3)

- Appendices: Literature search strategies and a summary of human studies of $H$. pylori infection and pancreatic and colorectal cancer 
The substance profile includes a description of the substance, discussion of exposure-related data, a summary of the scientific information considered key to its listing, and applicable current federal regulations and guidelines to limit exposure. If $H$. pylori is listed in the 15 th $\mathrm{RoC}$, then the substance profile (but not the other sections of the monograph) will become part of the RoC. The profile is written for a broad audience.

\subsection{Methods for Conducting the Cancer Hazard Evaluation}

As outlined in the concept document, NTP conducted several problem-formulating activities. These included searching the peer-reviewed literature (1) to determine the extent of U.S. exposure to $H$. pylori and (2) to identify any potential controversies concerning IARC's assessment or any reports of cancer studies published since the IARC review whose findings were not consistent with findings from the earlier studies. Based on these literature searches, no information was identified that would argue against using the IARC assessment as the scientific basis for applying the RoC listing criteria and reaching a listing recommendation. NTP did not conduct its own systematic review of the primary cancer studies in humans and experimental animals.

The scientific information in the substance profile and cancer prevention strategies sections underwent scientific review and quality assurance review by a separate reviewer. The information in the profile was checked against the cited reference (e.g., IARC monograph, primary reference, review, or meta-analysis). Any discrepancies were resolved between the writer and the reviewer through discussion and reference to the original data source.

\subsubsection{Selection of the Literature}

NTP supplemented the IARC assessment and peer review of the cancer studies in humans and experimental animals and mechanistic studies (IARC 2012) with recent reviews or meta-analyses on cancer and mechanistic studies and exposure information. NTP also reviewed individual studies (cited in reviews, the IARC monograph, or other publications) when information in the IARC monograph was not clear or was related to a specific scientific issue.

Details on the literature search procedures and search terms are available in Appendix A.

\subsubsection{Evaluation of Human Cancer Studies}

NTP applied the RoC listing criteria (shown at the end of Section 1.3) to the body of literature to reach a decision on the level of evidence (sufficient, limited, or inadequate) for carcinogenicity based on cancer studies in humans. Human cancer studies on $H$. pylori infection were reported in the most recent IARC monograph on H. pylori (IARC 2012). NTP supplemented this information with a few more-recent studies that addressed key issues, such as information regarding chronic infection.

NTP focused on the two cancer outcomes for which IARC concluded there was sufficient evidence of carcinogenicity from studies in humans: stomach cancer and gastric mucosaassociated lymphoid tissue (MALT) lymphoma (IARC 2012), Tables 2.1, 2.2, 2.3, 2.4, 2.5, 2.6, and 2.7). Evidence was considered to be lacking for $H$. pylori as a cause of esophageal cancer (adenocarcinoma). In evaluating the human cancer data, NTP considered (1) IARC workinggroup comments on the strengths and limitations of the studies, (2) the consistency of a positive 
association across studies, (3) patterns such as exposure-response or latency relationships, (4) effect modifiers or co-factors, and (5) whether the association across studies could be explained by chance, bias, or confounding. The science supporting the NTP level-of-evidence conclusions is captured in the substance profile (Section 2).

With respect to other types of cancer, the IARC working group expressed concerns about the quality of the studies or the small numbers of studies available (IARC 2012). NTP also reviewed recent meta-analyses, systematic reviews, and other reviews evaluating the association of H. pylori infection with other types of cancer, primarily pancreatic and colorectal cancer. In general, primary studies on these two types of cancer were identified from the meta-analyses or cited references. Based on the review of recent studies and of the IARC monograph, NTP concluded that no formal cancer hazard evaluation of pancreatic or colorectal cancer was warranted. A short summary of the updated findings on pancreatic and colorectal cancer is provided in Appendix B.

\subsubsection{Evaluation of Cancer Studies in Experimental Animals}

NTP applied the RoC listing criteria to the body of literature to reach a decision on the level of evidence (sufficient or not sufficient) from cancer studies in experimental animals. NTP accepted IARC's conclusions concerning the association between $H$. pylori infection and specific types of tumors (e.g., gastric adenocarcinoma and gastric lymphoma) in various animal models to determine whether the increases in tumors occurred at multiple tissue sites or in multiple species, or whether tumors occurred to an unusual degree with respect to incidence, site, type of tumor, or age at onset. In evaluating the data on cancer in experimental animals, NTP considered sources of heterogeneity across studies, such as differences in $H$. pylori strain, animal strain, or experimental methods, such as study duration.

\subsubsection{Evaluation of Mechanistic and Other Relevant Data}

The objective of the section on mechanistic and other relevant data is to provide a concise overview of the pathogenesis of $H$. pylori chronic infection and potential mechanisms of H. pylori carcinogenicity. As mentioned above, the substance profile is written for a broad audience, and its purpose is to provide an overview of the information that was key to the listing recommendation. Therefore, this section does not provide a detailed, comprehensive assessment of the mechanistic data or develop proposed modes of action. However, the section does evaluate whether the available mechanistic data provide biological plausibility for the findings observed in humans.

\subsubsection{Overall Evaluation and Listing Recommendation}

The evidence from the cancer studies in humans and experimental animals was integrated with the assessment of the mechanistic and other relevant data. The RoC listing criteria were then applied to the body of knowledge to reach a listing recommendation regarding chronic infection with H. pylori. 


\section{RoC Listing Criteria}

\section{Known to Be Human Carcinogen}

There is sufficient evidence of carcinogenicity from studies in humans*, which indicates a causal relationship between exposure to the agent, substance, or mixture, and human cancer.

\section{Reasonably Anticipated to Be Human Carcinogen}

There is limited evidence of carcinogenicity from studies in humans*, which indicates that causal interpretation is credible, but that alternative explanations, such as chance, bias, or confounding factors, could not adequately be excluded, OR

there is sufficient evidence of carcinogenicity from studies in experimental animals, which indicates there is an increased incidence of malignant and/or a combination of malignant and benign tumors (1) in multiple species or at multiple tissue sites, or (2) by multiple routes of exposure, or (3) to an unusual degree with regard to incidence, site, or type of tumor, or age at onset, OR

there is less than sufficient evidence of carcinogenicity in humans or laboratory animals; however, the agent, substance, or mixture belongs to a well-defined, structurally related class of substances whose members are listed in a previous Report on Carcinogens as either known to be a human carcinogen or reasonably anticipated to be a human carcinogen, or there is convincing relevant information that the agent acts through mechanisms indicating it would likely cause cancer in humans.

Conclusions regarding carcinogenicity in humans or experimental animals are based on scientific judgment, with consideration given to all relevant information. Relevant information includes, but is not limited to, dose response, route of exposure, chemical structure, metabolism, pharmacokinetics, sensitive sub-populations, genetic effects, or other data relating to mechanism of action or factors that may be unique to a given substance. For example, there may be substances for which there is evidence of carcinogenicity in laboratory animals, but there are compelling data indicating that the agent acts through mechanisms which do not operate in humans and would therefore not reasonably be anticipated to cause cancer in humans.

*This evidence can include traditional cancer epidemiology studies, data from clinical studies, and/or data derived from the study of tissues or cells from humans exposed to the substance in question that can be useful for evaluating whether a relevant cancer mechanism is operating in people.

\subsection{Method for Developing the Section on Prevention of $\boldsymbol{H}$. pylori- associated Cancer}

The purpose of the section is to provide information and summarize studies and expert working group recommendations related to the prevention of $H$. pylori-associated gastric cancers. The IARC working group report, "Helicobacter pylori Eradication as a Strategy for Preventing Gastric Cancer," served as the basis for Section 3 of the monograph (IARC 2014). The information was supplemented with new studies that evaluated the effectiveness of screening and eradication, cost-benefit analysis, and expert or government recommendations or guidelines. NTP did not make an assessment of the studies or provide its own recommendations or policies. The scientific information in the cancer prevention strategies sections underwent scientific review and quality assurance review by a separate reviewer, in a process similar to that described for the substance profile. 


\section{Helicobacter pylori (Chronic Infection) Substance Profile}

The substance profile provides a summary of the carcinogenicity information supporting NTP's listing recommendation for Helicobacter pylori, together with information on biological properties, detection methods, human exposure, and regulations to limit exposure. The exposure information includes data on transmission and risk factors, non-cancer diseases, treatment, and prevention.

\subsection{Biological Properties}

H. pylori is a gram-negative, spiral- (or helical-) shaped, multi-flagellated bacterium that has infected humans for more than 58,000 years. It is a member of the family Helicobacteraceae, which includes over 24 Helicobacter species that colonize gastric or enterohepatic tissues (i.e., intestinal tract, biliary tree, and liver). Some gastric Helicobacter species from animals that can also infect humans include $H$. bizzozeroni, $H$. salomonis, $H$. felis, $H$. canadensis, and $H$. suis (IARC 2012). Some Helicobacter species that cause non-gastric diseases (primarily liver diseases) in humans include H. hepaticus, H. pullorum, and H. bilis (Mateos-Muñoz et al. 2013).

H. pylori colonizes the mucosal surface of the body (corpus) and the lower portion (antrum) of the stomach. Colonization involves an interaction between the proteins of the bacterium's outer membrane and the epithelial cells of the stomach lining. One of the major $H$. pylori proteins involved in colonization is blood group antigen binding adhesin (BabA), which binds to blood group antigen A (IARC 2012). Although $H$. pylori triggers an immune response, the infected individual usually is unable to clear the infection; without treatment, an established infection usually lasts for the individual's lifetime (Logan and Walker 2001; Testerman and Morris 2014).

All H. pylori strains produce the enzyme urease, which converts urea to ammonia and carbon dioxide, raising the $\mathrm{pH}$ (decreasing the acidity) of the surrounding area. A neutral $\mathrm{pH}$ environment thus is created in the mucosal layer adjacent to the surface epithelium of the stomach, allowing the bacterium to grow (Testerman and Morris 2014). Other properties of the bacterium also facilitate a persistent infection. Its helical shape and flagella help it to propel itself through the viscous mucosa, and a chemotaxis system (by which an organism moves in response to a chemical stimulus) helps the bacterium avoid the acidic stomach environment and stay closer to the surface epithelium. A non-toxic lipopolysaccharide component of the bacterium's outer membrane may help reduce the infected individual's inflammatory response to the infection. After antibiotic treatment, H. pylori can sometimes be detected in the upper part of the stomach (Sachs et al. 2011).

The H. pylori genome codes for several virulence factors, including cytotoxin-associated gene A product (CagA) and vacuolating cytotoxin A (VacA), which vary geographically and across strains (IARC 2012; Yamaoka and Graham 2014). Moreover, there are variants of $H$. pylori CagA producing strains, such as strains that differ in types or numbers of motifs, that are involved in binding to host targets and increased activities (i.e., EPIYA motifs). These variant strains have different geographical distributions (Cover 2016). Humans can be infected with several $H$. pylori strains, which may then exchange DNA, promoting the spread of virulence factors and antibiotic resistance (IARC 2012). 


\subsection{Detection}

Numerous methods for diagnosing and screening for $H$. pylori infection are available, including assays to detect the bacterium itself, its DNA, antigens, antibodies, and urease activity (Table 2-1). The types of samples used in these tests range in invasiveness from biopsy samples taken during endoscopy, to blood samples, to collection of saliva, stool, urine, and expired air (Diaconu et al. 2017; Kato et al. 2001; Testerman and Morris 2014). These methods are summarized in the table below. Biopsy samples can also be evaluated for gastric pathology. All of these tests have moderate to high sensitivity ( $80 \%$ to $100 \%)$ and specificity $(75 \%$ to $100 \%)$; however, sensitivity and specificity may vary depending on the condition of the patient, and some methods require several samples. Sensitivity and specificity may also vary by population under study (Biranjia-Hurdoyal and Seetulsingh-Goorah 2016). The method of detection used depends in part on the purpose of the testing (e.g., selection of treatment method or population studies), cost and technical skills, and patient considerations, such as age.

Table 2-1. Methods for Detection of $\boldsymbol{H}$. pylori Infection

\begin{tabular}{|c|c|c|c|}
\hline Test & Agent & Type of Sample & $\begin{array}{r}\text { Comment } \\
\end{array}$ \\
\hline \multirow{3}{*}{$\begin{array}{l}\text { Histology: staining } \\
\text { (e.g., Diff-Quik, } \\
\text { Giemsa, hematoxylin } \\
\text { and eosin) }\end{array}$} & \multirow[t]{3}{*}{ H. pylori organism } & \multirow[t]{3}{*}{ Stomach tissue biopsy } & Sensitivity: 93\%-96\% \\
\hline & & & Specificity: 98\%-99\% \\
\hline & & & $\begin{array}{l}\text { Several samples needed; high cost; } \\
\text { should be performed only on } \\
\text { selected samples, such as from } \\
\text { patients with gastritis or using } \\
\text { certain types of antibiotics }\end{array}$ \\
\hline \multirow[t]{3}{*}{ Culture } & \multirow[t]{3}{*}{ H. pylori organism } & \multirow[t]{3}{*}{ Stomach tissue biopsy } & Sensitivity: $80 \%-98 \%$ \\
\hline & & & Specificity: $\sim 100 \%$ \\
\hline & & & $\begin{array}{l}\text { Used for antimicrobial sensitivity } \\
\text { testing; high cost }\end{array}$ \\
\hline \multirow[t]{2}{*}{ Rapid urease testing } & \multirow{2}{*}{$\begin{array}{l}\text { H. pylori activity (active } \\
\text { organisms) }\end{array}$} & \multirow[t]{2}{*}{ Stomach tissue biopsy } & Sensitivity: 88\%-95\% \\
\hline & & & Specificity: $95 \%-\sim 100 \%$ \\
\hline $\begin{array}{l}\text { Molecular methods } \\
\text { (e.g., polymerase chain } \\
\text { reaction) }\end{array}$ & H. pylori DNA or RNA & $\begin{array}{l}\text { Stomach tissue biopsy; } \\
\text { stool, saliva, or oral- } \\
\text { cavity specimens }\end{array}$ & Sensitivity and specificity $>95 \%$ \\
\hline \multirow{3}{*}{$\begin{array}{l}\text { Serology testing using } \\
\text { H. pylori antigens: } \\
\text { enzyme-linked } \\
\text { immunosorbent assay } \\
\text { (ELISA), immunoblot }\end{array}$} & \multirow{3}{*}{$\begin{array}{l}\text { H. pylori antibodies } \\
\text { (mainly immunoglobulin } \\
\mathrm{G}[\mathrm{IgG}] \text { ) }\end{array}$} & \multirow[t]{3}{*}{ Serum or plasma } & Sensitivity: $85 \%-96 \%$ \\
\hline & & & Specificity: $75 \%-95 \%$ \\
\hline & & & $\begin{array}{l}\text { False-negative results can occur } \\
\text { with underlying atrophic gastritis or } \\
\text { gastric cancer or lifelong infections }\end{array}$ \\
\hline \multirow[t]{2}{*}{ Urea breath test } & \multirow{2}{*}{$\begin{array}{l}\text { H. pylori urease activity } \\
\text { (active infection) by } \\
\text { measuring carbon } \\
\text { dioxide }\left(\mathrm{CO}_{2}\right)\end{array}$} & \multirow[t]{2}{*}{ Expired air } & Sensitivity: 90\%-99\% \\
\hline & & & Specificity: $88 \%-98 \%$ \\
\hline \multirow{3}{*}{$\begin{array}{l}\text { Stool antigen test (e.g., } \\
\text { ELISA, immunocards) }\end{array}$} & \multirow{3}{*}{$\begin{array}{l}\text { H. pylori antigens (active } \\
\text { infection) }\end{array}$} & \multirow{3}{*}{ Stool } & Sensitivity: 94\% \\
\hline & & & Specificity: $92 \%$ \\
\hline & & & Recommended for children \\
\hline
\end{tabular}

Sources: Diaconu et al. (2017); Reynders et al. (2012); Testerman and Morris (2014). 
Serological tests (such as ELISA or immunoblot) to detect H. pylori antibodies are widely available and relatively inexpensive. They are used in epidemiological and prevalence studies and are recommended for screening and treatment programs to prevent chronic disease (Areia et al. 2013). Serology tests are not recommended for low prevalence areas due to low specificity (Chey et al. 2017). Antibodies to H. pylori can persist for life, so these tests thus detect both past and current infections. An advantage of serological tests is that they are not affected by recent antibiotic use or acid-suppression therapy (Testerman and Morris 2014); however, they are not useful for measuring antibiotic treatment efficacy (Diaconu et al. 2017), as antibody titers are slow to fall. The sensitivity and specificity of serological tests depends on the antigens used in the assay, the type of assay (e.g., ELISA vs. immunoblot), the immunoglobulin class tested (mainly IgG, but also IgA), and factors that vary among infected individuals (González et al. 2012; Reynders et al. 2012). False-negative results can occur in individuals with advanced stomach diseases (e.g., atrophic gastritis) or cancer, because the bacteria are cleared from the mucosa of the stomach as the disease progresses. Case-control studies using ELISA may therefore underestimate the risk associated with $H$. pylori infection, because they will underestimate the prevalence in case but not control subjects (González et al. 2012; IARC 2012). Studies using immunoblot with multiple antigens have high sensitivity $(95 \%$ to $96 \%)$ and specificity (93\% to 96\%) for detecting H. pylori infection (Mitchell et al. 2008; Simán et al. 2007).

\subsection{Exposure}

More than half of the world's population, approximately 4.4 billion in 2015, are infected with H. pylori (Hooi et al. 2017). However, infection rates vary substantially within and among countries. In general, infection rates are related to socioeconomic status and levels of hygiene and are highest in low-income countries. Age-adjusted prevalence rates are particularly high (70\% to 87\%) in some countries in Africa, Latin America, the Caribbean, and Asia.

In the United States, approximately $30 \%$ to $36 \%$ of people are infected with $H$. pylori, the highest (ranging from $42 \%$ to up to $77 \%$ ) prevalence being found among minority groups (e.g., the Alaskan indigenous population, Hispanics, and African Americans) and individuals born outside the United States, especially recent Asian immigrants (Hooi et al. 2017; Khalifa et al. 2010; Krueger et al. 2015; Siao and Somsouk 2014). The lowest prevalence is among nonHispanic Whites with approximately $17 \%$ of people infected according to NHANES data (Krueger et al. 2015), although some more recent smaller studies report that this may be as low as 9\% among Texans (Long Parma et al. 2017). Moreover, the prevalence of more virulent strains may be higher among minorities; for example, in a study of mostly low-income individuals in the southeastern United States, the risk of CagA-positive infection was higher among African-Americans than whites (Epplein et al. 2011).

The prevalence of $H$. pylori infection increases with increasing age (Krueger et al. 2015); however, the age of peak prevalence varies geographically with peak prevalence occurring at a younger age in lower income countries (50 years old) compared to higher income countries (over age 60). Geographical differences in $H$. pylori prevalence may be related, in part, to differences in the rate of acquisition early in life (Khalifa et al. 2010; Malnick et al. 2014). In low-income countries, initial infection often occurs in early childhood and chronic infection continues through adulthood. In contrast, in high-income countries, infection rates are low among young children and adolescents. The lower rate of infection among children may be due to the fact that 
prevalence rates in most of the world (e.g., especially the United States, Korea, and Japan) have decreased with each successive generation (referred to as the "birth cohort effect") but have remained stable in many lower-income countries (such as in Latin and South America). The decline in H. pylori prevalence is related to access to clean water, improvements in sanitation, and improved household hygiene (Balakrishnan et al. 2017). Although there have been decreases in $H$. pylori infection in many countries, the prevalence remains high in adults.

Areas of high prevalence of $H$. pylori are not always directly correlated with high risk areas of gastric cancer, e.g., H. pylori prevalence but not gastric cancer incidence is high in Africa (Hooi et al. 2017). In a study in Colombia, two populations with different risks of stomach cancer (high and low) had similar prevalence patterns of $H$. pylori infection at an early age, suggesting that age of acquisition of infection may not play a major role in explaining gastric cancer risk (Camargo et al. 2004). Geographical differences in gastric cancer incidence may be explained in part by H. pylori genotypes, co-exposures (such as diet), and patients characteristics (for more information, see Carcinogenicity).

\subsubsection{Transmission}

Data from the U.S. National Health and Nutrition Examination Survey (NHANES) suggest that risk factors for $H$. pylori infection include age, race or ethnicity (minority), socioeconomic status (low family income and lower education level), and crowded housing (Krueger et al. 2015). Studies in other countries have also identified age, socioeconomic status, crowding, and poor sanitation as major risk factors and have suggested that gender and genetic predisposition also may influence $H$. pylori prevalence rates (Khalifa et al. 2010).

The bacterium is spread by person-to-person contact, especially among family members. This occurs primarily via oral-to-oral transmission and possibly via gastro-oral transmission mediated by refluxed gastric juice or fecal-oral transmission. H. pylori has been isolated from the oral cavity, gastric juices, and fecal samples (Khalifa et al. 2010). A meta-analysis of 22 studies found that $H$. pylori infection in the oral cavity was significantly more common among subjects with gastric $H$. pylori infection than among subjects without gastric $H$. pylori infection (Zou and Li 2011).

H. pylori can also be transmitted indirectly by drinking of contaminated water or possibly in food or from animal reservoirs (Aziz et al. 2015; Bui et al. 2016; IARC 2012; Khalifa et al. 2010). The bacterium has been detected in surface, ground, and well water in the United States and in treated municipal, tap, well, and bottled water in other countries (such as Peru and Sweden), and H. pylori can remain viable in chlorinated water [reviewed by Aziz et al. (2015); IARC (2012)]. The U.S. Environmental Protection Agency considers H. pylori a drinking-water contaminant and a candidate for possible regulatory action under the Safe Drinking Water Act (Krueger et al. 2015; USEPA 2016). Some epidemiological studies, including a study using NHANES data (for people aged 3 to 19) found that using well water or other unpurified water is a risk factor for H. pylori infection (Aziz et al. 2015; Khalifa et al. 2010; Krueger et al. 2015). In Japan, H. pylori prevalence was substantially lower in a cohort of individuals born between the 1960s and 1980s (14\%) than in cohorts born between 1927 (54\%) and 1949 (42\%), which could be the result of improvements in sanitary conditions, such as the introduction of municipal water supply in the 1950 s to 1970 s (Leja et al. 2016). NHANES data also indicated that soil-related occupations among adults are a risk factor for $H$. pylori infection, which suggests an environmental route of 
transmission (Krueger et al. 2015). However, other factors (country of birth, childhood poverty/crowding, race-ethnicity) are most likely more important for transmission of $H$. pylori in the United States.

\subsubsection{Diseases (Noncancer), Treatment, and Prevention}

In 2005, the Nobel Prize in Physiology or Medicine was awarded to Barry Marshall and Robin Warren for their discovery that an infectious agent, H. pylori, causes gastritis and peptic ulcers (up to $80 \%$ of gastric ulcers and over $90 \%$ of duodenal ulcers) (Nobel Prize 2005). H. pylori infection is also associated with some non-stomach diseases, such as iron-deficiency anemia and immune thrombocytopenia purpura (a tendency to bleed easily because of reduced numbers of blood platelets), and may be associated with non-ulcer dyspepsia (indigestion), although this association is not clear (AlMalki 2008; Dore et al. 2016; Testerman and Morris 2014).

Many different therapies are used in the United States, but the American College of Gastroenterology's Clinical Guideline for Treatment of H. pylori Infection update in 2017 (Chey et al. 2017) indicates that first-line regimens approved by the U.S. Food and Drug Administration (FDA) are either (1) clarithromycin triple therapy, with that antibiotic in combination with a proton-pump inhibitor (PPI) and a second antibiotic for 14 days, or (2) bismuth quadruple therapy, with a bismuth salt, a PPI, and two antibiotics for 10 to 14 days. Due to high levels of antibiotic resistance, clarithromycin triple therapy should only be considered a first line treatment in areas where resistance among $H$. pylori patients is known to be low. Eradication of $H$. pylori infection in an individual can be affected by (1) patient-related factors (e.g., adherence to the treatment regimen, smoking, diabetes, genetic factors influencing metabolism of PPIs, and past antibiotic use) and (2) $H$. pylori-related factors. The susceptibility of $H$. pylori to specific antibiotics is the most important determinant of successful $H$. pylori treatment, and patterns of resistance to specific antibiotics can vary geographically (Chey et al. 2017; Malfertheiner et al. 2017). If first-line treatment fails, second-line or salvage therapy generally is based on local antibiotic resistance rates (where known) and an individual's previous antibiotic use. Globally, H. pylori eradication rates have declined as antibiotic resistance rates have increased (Thung et al. 2016). Currently, no H. pylori vaccine is available (CDC 2016; FDA 2017). Vaccine development efforts are ongoing, but no large scale vaccine efforts are taking place (Sutton and Boag 2018; Zeng et al. 2015).

Randomized controlled trials (clinical studies with control groups that receive placebos) have shown that screening and treatment of $H$. pylori reduces stomach-cancer risk by approximately 35\% (Herrero et al. 2014; Park et al. 2013). Moreover, economic modeling studies, in both lowand high-prevalence countries, have shown that $H$. pylori eradication is cost-effective. However, effectiveness in reducing cancer risk depends on several factors, such as patient characteristics, screening methods, efficacy of $H$. pylori eradication, and the stage of $H$. pylori-associated gastric disease. $H$. pylori eradication may increase bacterial resistance to antibiotics, alter the normal gastrointestinal flora found in the body, and possibly increase the incidence of diseases for which H. pylori infection may offer protection, such as esophageal cancer and gastro-esophageal reflux disease (GERD). Numerous international and national working groups have recommended that planned programs should consider objective assessments of feasibility, effectiveness, program acceptance, cost-effectiveness, and adverse consequences relevant to the local area before implementation. (See Section 3 for more information on prevention strategies.) 


\subsection{Carcinogenicity}

This section reviews the evidence for carcinogenicity in humans (Section 2.4.1) and experimental animals (Section 2.4.2) and mechanistic data (Section 2.4.3) that are key to NTP's listing recommendation (Section 2.4.4).

\subsubsection{Cancer Studies in Humans}

Worldwide, stomach cancer is the fifth most common type of cancer and third leading cause of death from cancer, with most cases occurring in low- and middle-income countries.

Adenocarcinoma accounts for over $90 \%$ to $95 \%$ of all stomach cancer (Balakrishnan et al. 2017), which can be broadly classified by the location in the stomach where the cancer develops:

(1) cardia gastric cancer develops in the first portion of the stomach, closest to the esophagus, and (2) non-cardia gastric cancer develops in more distal parts of the stomach, closer to the small intestine. Gastric lymphoma, which consists primarily of gastric mucosa-associated lymphoid tissue (MALT) lymphoma and diffuse large B-cell lymphoma, accounts for approximately $2 \%$ to $8 \%$ of all stomach tumors (Park and Koo 2014; Zullo et al. 2010b). Gastric MALT lymphoma is a type of extranodal B-cell lymphoma (i.e., not arising in lymph nodes or other lymphoid tissue) that is low-grade, slow growing, and very rare (with a worldwide incidence of 1 to 1.5 cases per 100,000 people) (Pereira and Medeiros 2014).

\section{Stomach Cancer}

Evidence that H. pylori causes stomach (non-cardia gastric) cancer in humans is based on (1) consistent evidence from numerous epidemiological studies on stomach cancer, (2) a pooled analysis of 12 epidemiological studies, and (3) several meta-analyses (combined statistical analyses of the data from several different studies).

Cohort studies found that $H$. pylori-infected individuals were more likely to develop stomach cancer than were uninfected individuals (IARC 2012). These studies followed subjects with and without $H$. pylori infection for 4 to 10 years. Depending on the study, the subjects were either asymptomatic or had various types of stomach disease and were enrolled in various types of screening programs. Numerous nested case-control studies (case-control analyses conducted within cohorts of subjects), with follow-up times up to 15 years, provided evidence that the increased risk was specifically for non-cardia gastric cancer (IARC 2012). A pooled analysis of 12 of these nested case-control studies, which included 762 case subjects and 2,250 control subjects, matched to the case subjects by age, sex, and date of sample collection for $H$. pylori testing, found a risk factor of $2.97(95 \%$ confidence interval $[\mathrm{CI}]=2.34$ to 3.77$)$ for non-cardia gastric cancer and H. pylori infection (Helicobacter Cancer Collaborative Group 2001). The highest risk was for subjects followed for a longer time after enrollment (odds ratio $[\mathrm{OR}]=5.93$, $95 \% \mathrm{CI}=3.41$ to 10.30 for $\geq 10$ years of follow-up, compared with $\mathrm{OR}=2.39,95 \% \mathrm{CI}=1.82$ to 3.12 for $<10$ years of follow-up).

Similar findings of an excess risk of non-cardia gastric cancer were reported in a meta-analysis of data from eight studies (Huang et al. 2003). Nested case-control studies that either were published after the 2001 pooled analysis or had accrued more cases since the 2001 pooled analysis also found significantly elevated risks for non-cardia gastric cancer, confirming the association with $H$. pylori infection. 
Most epidemiological studies measured H. pylori infection status by the presence of antibodies to H. pylori (i.e., seropositivity). Higher risks for non-cardia gastric cancer (increased by over tenfold) were found when $H$. pylori seropositivity was measured by a more sensitive assay (immunoblot, rather than the ELISA method typically used) (González et al. 2012; Mitchell et al. 2008; Simán et al. 2007). In most studies that looked at infection with various strains of H. pylori, higher risks were found for infection with strains that produced CagA than for infection with CagA-negative strains. A meta-analysis of data on $H$. pylori-positive cases from nine studies found that CagA seropositivity approximately doubled the risk of non-cardia gastric cancer over that due to $H$. pylori infection alone (Huang et al. 2003). Some studies have evaluated gastric cancer risk for specific CagA variants (type and number of EPIYA motifs, see Properties); e.g., a single EPIYA-D motif was associated with increased gastric cancer in studies in Asia, whereas multiple EPIYA-C motifs were associated with increased gastric cancer risk in studies in the United States and Europe (Li et al. 2017).

Some studies found a higher risk of stomach cancer among $H$. pylori-infected individuals who smoked or who consumed salted, smoked, processed foods, or red meat, and a lower risk among those with diets high in vegetables or intake of vitamins, suggesting that these exposures (diet or types of food) may be co-factors for H. pylori-induced stomach cancer (Epplein et al. 2014; IARC 2012). Several studies controlled for known risk factors for stomach cancer, and increased risks were found in studies in various geographical locations, which increases confidence that the elevated risks observed in these studies are not explained by bias, chance, or confounding.

Evidence for a role of $H$. pylori in cardia gastric cancer is less clear and may be restricted to specific subtypes of cardia gastric cancer. Neither the Helicobacter Cancer Collaborative Group pooled analysis of nested case-control studies ( 274 cases and 827 controls) nor the meta-analysis by Huang et al. (2003) of 16 published studies found an excess risk of cardia gastric cancer and H. pylori infection. However, a meta-analysis of all types of studies (primarily case-control studies) found that $H$. pylori infection increased the risk of cardia gastric cancer in high-risk countries (adjusted relative risk $[\mathrm{RR}]=1.59,95 \% \mathrm{CI}=1.03$ to $1.45 ; 11$ studies) but not in lowrisk countries ( $\mathrm{RR}=0.80,95 \% \mathrm{CI}=0.63$ to $1.02 ; 14$ studies) (Cavaleiro-Pinto et al. 2011). The differences in the risk patterns might be due to different subtypes of cardia gastric cancer or inclusion of adenocarcinoma of the esophagus or the gastroesophageal junction with cardia gastric cancer; however, few studies have addressed these anatomical distinctions (Malfertheiner et al. 2017).

\section{Gastric MALT Lymphoma}

Evidence that $H$. pylori causes gastric MALT lymphoma comes primarily from 16 intervention (non-controlled) studies [as reviewed by IARC (2012)], which found that eradication of $H$. pylori infection in gastric MALT lymphoma patients resulted in high rates (62\% to $100 \%)$ of complete remission of the cancer. A pooled analysis of patients with gastric MALT lymphoma from 32 studies found that remission occurred in approximately $78 \%$ of the patients who were cured of H. pylori infection (Zullo et al. 2010a). Because of the rarity of this cancer, the number of observations is limited. Two small case-control analyses (a prospective nested case-control study and a hospital-based case-control study) found a positive association between $H$. pylori infection and gastric MALT lymphoma, which provides additional support for a causal relationship [Parsonnet et al. (1994) and de Sanjose et al. (2004), as cited by IARC (2012)]. 


\subsubsection{Cancer Studies in Experimental Animals}

H. pylori infection (orally administered by gavage) caused malignant tumors in two different types of stomach tissue in rodents. Importantly, the types of cancer observed in animals infected with $H$. pylori-gastric tumors and gastric lymphoma - are similar to those linked with $H$. pylori infection in humans. Some of these animal models are thought to mimic tumor progression in humans, as they also show similar types of $\mathrm{H}$. pylori-induced gastric lesions.

H. pylori infection increased the incidences of malignant stomach tumors (mainly adenocarcinoma and some carcinoid) (1) in Mongolian gerbils in some, but not all, studies and (2) in transgenic (genetically altered) mice. Differences in the findings in gerbils may be due to differences in the H. pylori strain, gerbil strain, dose, and/or duration of exposure. A gerbiladapted strain of $H$. pylori (derived from a human gastric ulcer strain) increased the incidence of malignant stomach tumors in Mongolian gerbils as early as 8 to 12 weeks after infection [Franco et al. (2005); Franco et al. (2008); and Romero-Gallo et al. (2008), as cited by IARC (2012)]. In general, findings in gerbils infected with other $\mathrm{H}$. pylori strains were mixed; positive findings were more common in studies of longer duration, conducted in Asia, or using higher doses. IARC (2012) noted that the genetic background of the Mongolian gerbils may have evolved differently among colonies established in different geographic locations and that the pathology grading varied among studies. H. pylori infection caused gastric carcinoma in several studies in INS-GAS transgenic mice, which have been genetically modified to produce more gastrin (a peptide that increases the secretion of gastric acid). In studies of other types of transgenic mice (TGF- $\beta$ - or p27-deficient mice, which have increased susceptibility to carcinogens), H. pylori infection increased the incidence of combined gastric dysplasia (a precancerous lesion) and carcinoma (IARC 2012). Two studies, one in Mongolian gerbils [Romero-Gallo et al. (2008), as cited by IARC (2012)] and the other in transgenic mice [Lee et al. (2008), as cited by IARC (2012)], found that $H$. pylori eradication therapy, when given early, inhibited the development of malignant stomach tumors (adenocarcinoma), which increases confidence that $H$. pylori causes stomach cancer in experimental animals.

There is strong evidence that $H$. pylori given in combination with other carcinogens ( $N$-methyl$N$-nitrosourea [MNU], $N$-methyl- $N$ '-nitro- $N$-nitrosoguanidine, or ethylnitronitrosoguanidine) increased the incidences of stomach tumors over those in rodents (IARC 2012) and non-human primates (Liu et al. 2009) exposed only to the other carcinogens. Early H. pylori eradication therapy reduced the incidence of stomach tumors (adenocarcinoma) induced by combined administration of $H$. pylori and MNU [Nozaki et al. (2002), as cited by IARC (2012)]. The addition of a high-salt diet also increased the incidence of stomach tumors in $\mathrm{H}$. pylori-infected gerbils.

H. pylori infection caused gastric lymphoma in two different strains of inbred mice [Wang et al. (2003), as cited by IARC (2012)] and in neonatal mice that had had their thymus glands removed (Fukui et al. 2004). In the latter study, all of the mice developed gastric MALT lymphoma by the age of 12 months.

\subsubsection{Mechanisms of Carcinogenesis and Other Relevant Data}

The mechanisms by which $H$. pylori causes stomach cancer are complex and involve many different factors. They involve interactions between (1) direct effects of the toxic action of H. pylori virulence factors (e.g., the effects of CagA, VacA, and outer inflammatory protein), 
(2) indirect effects due to modification of the infected individual's inflammatory responses to chronic $H$. pylori infection, which can be influenced by the genes regulating immune processes and by lifestyle and dietary habits, and (3) changes in acid secretion in the stomach. Collectively, this information may help to explain why only a small fraction of $H$. pylori-infected individuals ( $10 \%$ in high-risk countries and $1 \%$ to $3 \%$ in other countries) develop stomach cancer (Balakrishnan et al. 2017; IARC 2012; Servetas et al. 2016).

H. pylori infection is usually acquired in childhood and can cause inflammation or irritation of the lining (mucosa) of the stomach (chronic infection, or gastritis). This gastritis is associated with recruitment of various types of immune cells (e.g., neutrophils and lymphocytes).

Progression to more serious stomach diseases, such as ulcers, MALT lymphoma, and non-cardia gastric cancer, occurs as the infected individual grows older, and it depends on factors specific to the infected individual and to the bacterium, as well as on the acidity of the stomach environment. Chronic inflammation of the stomach mucosa (chronic atrophic gastritis, occurring mainly in the corpus of the stomach) is associated with changes in the types of tissues and cells in the stomach (IARC 2012).

Most individuals infected with $H$. pylori do not develop symptoms; however, in some people, atrophic gastritis can progress to stomach ulcers or precancerous lesions (e.g., intestinal metaplasia and dysplasia), which can progress to stomach cancer (adenocarcinoma). Several studies provided evidence that progression of gastric lesions increased the risk of $H$. pyloriinduced gastric cancer. A cohort study of middle-aged Japanese men found that the risk of $H$. pylori-induced gastric cancer relative to that in uninfected men increased with increasing severity of $H$. pylori lesions (i.e., from non-chronic atrophic gastritis to chronic atrophic gastritis to metaplastic gastritis (Ohata et al. 2004; Yoshida et al. 2014). A German cohort study found that having chronic atrophic gastritis was associated with a fivefold increase in the risk of noncardia gastric cancer (Chen et al. 2016). In this study, serological biomarkers were used to assess the stages of gastritis.

In infected individuals with higher acid secretion, gastritis is more likely to develop in the lower part of the stomach (antrum-predominant gastritis) and can progress to ulcers in the small intestine (duodenal ulcers). Gastric MALT lymphoma can develop from gastritis in any part of the stomach (pangastritis) (Conteduca et al. 2013; IARC 2012; Ishaq and Nunn 2015; Testerman and Morris 2014).

H. pylori-induced chronic inflammation can lead to oxidative stress, aberrant expression of genes (e.g., suppression of the expression of some genes and enhancement of the expression of others, primarily via the process of aberrant DNA methylation), and disruption of enzymes involved in repairing DNA damage. This results in increased DNA damage in cells of the stomach lining (epithelial cells) and can result in mutation and genetic instability (Graham 2015; Maeda et al. 2017; Servetas et al. 2016). In addition, H. pylori either directly or indirectly (e.g., via inflammation) targets biological pathways involved in cell turnover, survival, and proliferation (e.g., by inhibiting tumor-suppressor genes). H. pylori also initiates changes in the characteristics of stomach epithelial cells (known as the "epithelial to mesenchymal transition") that enable the cells to proliferate as cancer cells do (Servetas et al. 2016).

Some of these biological effects vary depending on virulence factors, the production of which can differ among $H$. pylori strains. For example, some $H$. pylori strains (such as CagA-positive 
strains) can induce a high degree of chronic inflammation (Figura et al. 2016). Moreover, studies in animals and cells have shown that CagA is an oncoprotein (i.e., when the gene is transferred into cells or animals, it causes gastric cells to proliferate and develop into tumors) (Wang et al. 2015). Virulence factors in H. pylori strains vary geographically, which may help to explain geographical patterns of stomach cancer risk (Wang et al. 2015; Yamaoka and Graham 2014). As discussed above, cancer risks are higher for CagA-positive H. pylori infection than for CagAnegative infection. A German cohort study (Chen et al. 2016) found that people with H. pylori CagA-positive infection who had markers in their blood for chronic atrophic gastritis had a much higher risk of developing non-cardia gastric cancer (hazard ratio $[\mathrm{HR}]=32.4,95 \% \mathrm{CI}=7.6$ to 137.6) than did people without these two risk factors. These biological effects (chronic inflammation, changes in gene expression, mutations, genomic instability, and cellular proliferation) are associated with carcinogenesis.

\subsubsection{NTP's Listing Recommendation}

Helicobacter pylori (chronic infection) is known to be a human carcinogen based on sufficient evidence of carcinogenicity from studies in humans. This conclusion is based on epidemiological studies showing that $H$. pylori infection causes stomach cancer (especially non-cardia gastric cancer) and a specific type of lymphoma in the stomach (gastric MALT lymphoma).

H. pylori is estimated to cause $89 \%$ of non-cardia gastric cancer and $92 \%$ to $98 \%$ of all gastric MALT lymphoma cases. It is responsible for approximately 780,000 cancer cases (primarily gastric cancer) worldwide each year, accounting for $6.2 \%$ of all cancer cases (Plummer et al. 2015; Testerman and Morris 2014). Mechanistic and toxicological data indicate that chronic infection of the stomach with $H$. pylori is required for carcinogenicity, and they demonstrate the biological plausibility of its carcinogenicity. Studies in experimental animals indicate that $H$. pylori induces types of tumors similar to those found in humans: adenocarcinoma and lymphoma of the stomach.

\subsection{Regulations}

\subsubsection{Department of Transportation (DOT)}

Infectious substances are considered hazardous materials, and special requirements have been set for marking, labeling, and transporting these materials.

\subsubsection{Food and Drug Administration (FDA, an Agency of Health and Human Services)}

Helicobacter pylori is listed as a qualifying pathogen having the potential to pose a serious threat to public health under the Generating Antibiotic Incentives Now (GAIN) title of the Food and Drug Administration Safety and Innovation Act (FDASIA). GAIN is intended to encourage development of new antibacterial and antifungal drugs for the treatment of serious or lifethreatening infections.

\subsubsection{Occupational Safety and Health Administration (OSHA)}

First-aid training program trainees must have adequate instruction in the value of universal precautions for minimizing exposure to blood and other potentially infectious material. 


\section{Prevention of $\boldsymbol{H}$. pylori-associated Cancer}

Stomach cancer is the fifth most common cancer worldwide, with around 1.3 million new cases occurring annually, and the third most common cause of death from cancer-it is estimated that over 800,000 people died of stomach cancer worldwide in 2015 (Fitzmaurice et al. 2017). An estimated $73 \%$ of all stomach-cancer cases are non-cardia gastric cancer (Colquhoun et al. 2015). Worldwide, $70 \%$ of all stomach-cancer cases occur in low-income countries. In low-risk areas, such as the United States, Europe, Australia, and New Zealand, the incidence of and mortality from stomach cancer show disparities, with minority, indigenous, and immigrant populations at higher risk (Balakrishnan et al. 2017; Epplein et al. 2011; SEER 2018; Taylor et al. 2014). In the United States, stomach cancer accounts for $1.7 \%$ of all new cancer cases, but some minority populations have a $40 \%$ to $50 \%$ higher risk (Bjorkman 2017; SEER 2018). In addition to disparities by geography and race, stomach-cancer incidence and mortality are higher in men than women; worldwide, the estimated age-standardized incidence rate in men is twice that in women (Forman and Sierra 2014; Herrero et al. 2014). Overall stomach-cancer incidence has decreased in recent years, by approximately $2 \%$ per year; however, recent evidence suggests it may be increasing in younger populations (Anderson et al. 2018). The estimated global burden of the disease is expected to increase in the next 10 to 15 years, primarily as a result of population growth and aging [Ferlay et al. (2013), as cited by IARC (2014)].

H. pylori infection has been established as a cause for non-cardia gastric cancer and gastric MALT lymphoma (IARC (2012); see Section 2) and may account for up to $6.2 \%$ of all cancer deaths worldwide (Plummer et al. 2015). Calculated population attributable fractions range from $75 \%$ to $89 \%$, indicating that a large majority of these cancer cases could be avoided if $H$. pylori exposure were eliminated (de Martel et al. 2012; Plummer et al. 2015; Song and Zhou 2015).

This section provides an overview of the state of science for prevention of $\mathrm{H}$. pylori-induced cancer, the cost-effectiveness of this prevention, issues and concerns for large-scale prevention programs, and current national and regional policies for stomach cancer prevention.

\subsection{Prevention of $\boldsymbol{H}$. pylori-induced Cancers: State of the Science}

Screening and treatment of $H$. pylori-infected individuals show promise as a method for the prevention of stomach cancer. Over the past 20 years, numerous studies have been conducted on the effectiveness of screening and treatment methods. Three screening methods and two types of treatment have been evaluated (see Section 3.1.1). The benefits of $H$. pylori eradication have been evaluated in 10 randomized controlled trials and at least 16 cohorts. These studies support eradication of $H$. pylori for the prevention of stomach cancer, and recent meta-analyses have confirmed these findings (see Section 3.1.2). Moreover, several economic analyses have determined that screening and treatment of $H$. pylori is cost-effective as a prevention method (see Section 3.1.3). Several issues and concerns relevant to the implementation of large-scale eradication efforts must be taken into account. These include antibiotic resistance, the likelihood of $H$. pylori reinfection, the possible inverse relationship between $H$. pylori infection and some other gastric illnesses, the presence of atrophic damage at the time of eradication, and the need to tailor treatment programs to specific geographic regions (see Section 3.1.4). 
Other methods of prevention of $H$. pylori-induced cancer include preventing the spread of H. pylori and developing a vaccine (see Section 2 for a discussion on the spread of $H$. pylori).

\subsubsection{Screening for and Treatment of $\boldsymbol{H}$. pylori Infection}

H. pylori screening and treatment have been identified as candidates for population-level intervention programs in high-prevalence areas, supported by several cost-benefit analyses; however, additional data are needed. Several methods exist for H. pylori population screening, including serology tests for H. pylori antibodies, a stool antigen test, and a urea breath test. Stool antigen and urea breath tests are more expensive and may be harder to implement at a population level. H. pylori serological tests (for antibodies) detect both past and present infections, and therefore are not useful for determining the efficacy of $H$. pylori treatment (Moayyedi 2014) (see Section 2 for more details on detection methods).

Treatment of $H$. pylori infection often can achieve a high rate of eradication. The most common treatment is a standard triple therapy, which includes a PPI, clarithromycin, and either amoxicillin or metronidazole antibiotics given for 1 to 2 weeks. This PPI triple therapy is relatively low-cost and widely available. Early reports suggested that this treatment resulted in eradication rates of over $90 \%$; however, rates more recently have fallen well below $80 \%$. In some locations in Europe, the eradication rate for the standard PPI triple therapy is as low as $25 \%$ to $60 \%$. This variability in effectiveness is likely due to the rise in antibiotic resistance, specifically to clarithromycin. In many parts of the world, clarithromycin resistance is so high that the clarithromycin-based PPI triple therapy is not recommended as the first-line treatment. Methods to improve the effectiveness of the PPI triple therapy have been proposed, such as increasing the dose by increasing the frequency of treatment, using second-generation PPIs, or increasing treatment duration [reviewed by Gisbert and Greenberg (2014)]. Another treatment currently recommended as a first-line therapy (concomitant therapy) adds metronidazole or nitroimidazole to the standard PPI treatment (Chey et al. 2017).

Another low-cost therapy (bismuth-containing quadruple therapy) combines bismuth salts, tetracycline, a PPI, and metronidazole for 14 days, with a reported eradication rate of over $80 \%$ to $90 \%$. Bismuth-containing quadruple therapy is now recommended as the first-line treatment in

areas of high clarithromycin resistance, while standard PPI triple therapy may be used in areas of low resistance. Although metronidazole resistance is high worldwide, the clinical impact of this resistance is low, and the quadruple therapy is effective when dose and duration are increased. Additional studies are needed on the effectiveness of bismuth-containing quadruple therapy as a first-line treatment. The unavailability of bismuth and tetracycline in many areas also must be considered for any population-level intervention programs. Because antibiotic resistance varies within populations, programs should use treatment regimens that have proven reliably effective in the target population and area, or methods based on the observed pattern of resistance [reviewed by Gisbert and Greenberg (2014) and Herrero et al. (2014)].

\subsubsection{Efficacy and Effectiveness of $\boldsymbol{H}$. pylori Eradication in Preventing Stomach Cancer}

\section{Gastric Cancer}

Since 1997, a number of cohort studies and randomized controlled trials have been conducted to determine the efficacy and effectiveness of $H$. pylori eradication therapy in preventing gastric 
cancer. These studies looked at the effectiveness of eradication among individuals who had never had stomach cancer (primary prevention) and among patients with previous endoscopic resection of early gastric cancer (secondary prevention, sometimes referred to as tertiary prevention). The cohort studies were generally conducted in Japan and Korea, with one study each in Taiwan and Finland, and enrolled between 50 and 8,000 participants, with follow-up times ranging from 2 to 10 years.

Since 2000, six randomized controlled trials have investigated the primary prevention of gastric cancer following $H$. pylori eradication therapy. These trials have been primarily in China, with one each in Colombia (Correa et al. 2000) and Japan (Saito et al. 2005); follow-up times ranged from 3 to 14.7 years. An additional three trials, one in Japan (Fukase et al. 2008) and two in South Korea (Choi et al. 2018; Choi et al. 2014b), looked at the efficacy of H. pylori eradication for the secondary prevention of gastric cancer, with follow-up times of approximately 3 to 6 years.

Taken together, the nine trials demonstrated the partial effectiveness of $H$. pylori eradication therapy in reducing the incidence of gastric cancer. These studies generally had a large number of total participants, but many had small numbers of cases in both study arms. Only two of the nine studies had follow-up times exceeding 10 years, which may explain the lack of significant findings in several studies. Furthermore, all of these trials used the standard PPI triple therapy for eradication, and not the bismuth-containing quadruple therapy, which may be more effective in areas with high levels of clarithromycin resistance. Finally, all but one trial took place in eastern Asia, which may limit the generalizability of the results to other populations. The results of the randomized controlled trials are summarized in Table 3-1. Additional data will be provided by several ongoing trials, as well as long-term follow-up of the current studies. Additional data on prevention efficacy may provide additional support for large-scale eradication programs.

Table 3-1. Randomized Controlled Trials of $H$. pylori Eradication and the Incidence of Gastric Cancer

\begin{tabular}{|c|c|c|c|}
\hline $\begin{array}{c}\text { References } \\
\text { Geographic } \\
\text { Location }\end{array}$ & $\begin{array}{l}\text { Study Population } \\
\text { No. of Subjects } \\
\text { Follow-up Duration }\end{array}$ & End Points & $\begin{array}{c}\text { RR, HR, or OR (95\% CI); } \\
\text { No. of Cases }\end{array}$ \\
\hline \multicolumn{4}{|c|}{ Individuals without gastric cancer } \\
\hline $\begin{array}{l}\text { Correa et al. (2000) } \\
\text { Colombia }^{\mathrm{b}}\end{array}$ & $\begin{array}{l}\text { Asymptomatic men and women } \\
\text { aged 29-69 with advanced } \\
\text { gastric lesions (CAG, IM, and } \\
\text { DYS); enrolled } 1991 \\
491 / 485 \\
6 \text { years }\end{array}$ & $\begin{array}{l}\text { Gastric cancer } \\
\text { IM regression } \\
\text { IM progression }\end{array}$ & $\begin{array}{l}{[1.48(0.25-8.83) ; 3 / 2} \\
\text { cases }^{\mathrm{c}} \\
3.1(1.0-9.3) \\
0.4(0.2-0.9)\end{array}$ \\
\hline $\begin{array}{l}\text { Wong et al. (2004) } \\
\text { China }\end{array}$ & $\begin{array}{l}\text { Asymptomatic men and women } \\
\text { aged } 35-65 \text { with mixed gastric } \\
\text { lesions; enrolled } 1994 \\
817 / 813 \\
7.5 \text { years }\end{array}$ & $\begin{array}{l}\text { Gastric cancer } \\
\text { All subjects } \\
\text { Baseline precancerous } \\
\text { lesions } \\
\text { No (62\%) } \\
\text { Yes (CAG, IM, DYS) }\end{array}$ & $\begin{array}{l}\mathrm{p}=0.02 ; 0 / 6 \\
\mathrm{p}=0.67 ; 7 / 5\end{array}$ \\
\hline
\end{tabular}




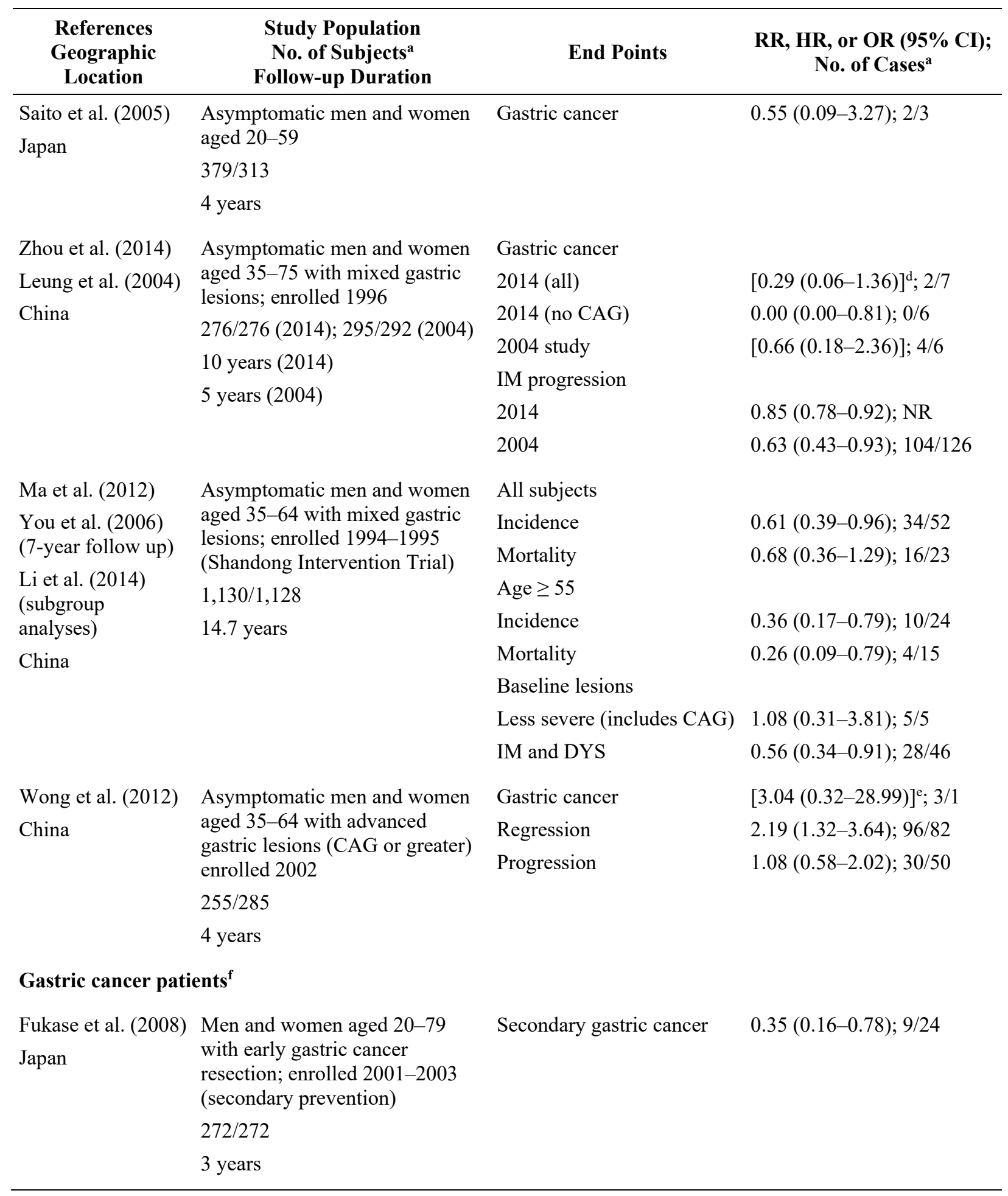




\begin{tabular}{|c|c|c|c|}
\hline $\begin{array}{l}\text { References } \\
\text { Geographic } \\
\text { Location }\end{array}$ & $\begin{array}{l}\text { Study Population } \\
\text { No. of Subjects } \\
\text { Follow-up Duration }\end{array}$ & End Points & $\begin{array}{c}\text { RR, HR, or OR }(95 \% \mathrm{CI}) \\
\text { No. of Cases }\end{array}$ \\
\hline \multirow{4}{*}{$\begin{array}{l}\text { Choi et al. (2014b) } \\
\text { South Korea }\end{array}$} & Men and women aged 20-75 & \multirow[t]{4}{*}{ Secondary gastric cancer } & \multirow{4}{*}{$\begin{array}{l}{[0.61(0.28-1.31)]^{\mathrm{d}} ; 10 / 17} \\
(\mathrm{p}=0.15 \text { by } \log \text { rank })\end{array}$} \\
\hline & $\begin{array}{l}\text { with early gastric cancer } \\
\text { resection; enrolled 2005-2011 } \\
\text { (secondary prevention) }\end{array}$ & & \\
\hline & $444 / 457$ & & \\
\hline & $\begin{array}{l}2.6-93.3 \text { months } \\
\text { (Median }=38 \text { months) }\end{array}$ & & \\
\hline \multirow{4}{*}{$\begin{array}{l}\text { Choi et al. (2018) } \\
\text { South Korea }\end{array}$} & Men and women aged 18-75 & \multirow[t]{4}{*}{ Secondary gastric cancer } & \multirow{4}{*}{$\begin{array}{l}0.50(0.26-0.94) ; 14 / 27 \\
p=0.03\end{array}$} \\
\hline & $\begin{array}{l}\text { with early gastric cancer } \\
\text { resection; enrolled 2003-2013 } \\
\text { (secondary prevention) }\end{array}$ & & \\
\hline & $194 / 202$ & & \\
\hline & $\begin{array}{l}\text { Median }=5.9 \text { years, } \\
\text { Maximum }=12.9 \text { years }\end{array}$ & & \\
\hline
\end{tabular}

$\mathrm{CAG}=$ chronic atrophic gastritis; $\mathrm{DYS}=$ dysplasia; $\mathrm{HR}=$ hazard ratio; $\mathrm{IM}=$ intestinal metaplasia; $\mathrm{IRQ}=$ interquartile range; $\mathrm{OR}=$ odds ratio; $\mathrm{RR}=$ relative risk.

${ }^{\text {aTreatment/placebo. }}$

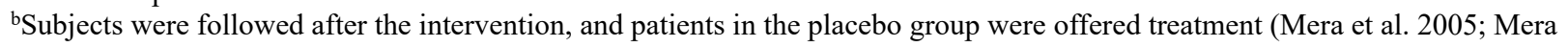
et al. 2017).

${ }^{\mathrm{c}}$ Effect estimate calculated by Ford et al. (2014) meta-analysis.

${ }^{\mathrm{d}}$ Effect estimate calculated by Lee et al. (2016) meta-analysis.

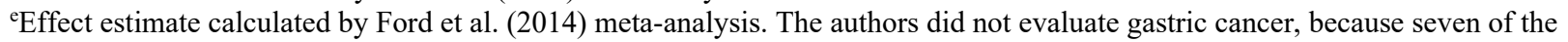
nine cancer cases across several treatment groups occurred during the treatment period.

fPatients with previous endoscopic resection of early gastric cancer.

The most informative studies were two large trials in China that evaluated primary prevention of gastric cancer. The Shandong Intervention Trial (Li et al. 2014; Ma et al. 2012; You et al. 2006) enrolled and randomized 2,258 H. pylori-seropositive subjects who were followed for 14.7 years, resulting in 34 cancer cases in the intervention group and 52 in the placebo group $(\mathrm{OR}=0.61$, $95 \% \mathrm{CI}=0.38$ to 0.96 ). The next-largest trial, also conducted in China, enrolled 1,630 H. pyloriseropositive participants who were followed for 7.5 years. A total of 7 cancer cases were seen in the intervention group and 11 in the placebo group ( $\mathrm{HR}=0.63,95 \% \mathrm{CI}=0.24$ to 1.52 ) (Wong et al. 2004). These studies stratified by the type of gastric lesion at baseline but defined the lesion categories differently. The Shandong Intervention Trial grouped chronic atrophic gastritis with less severe lesions and found that $H$. pylori eradication was effective in preventing gastric cancer among participants with precancerous lesions (intestinal metaplasia and dysplasia) at baseline, but not among patients with less severe lesions; however, few cases of gastric cancer were seen in either treatment arm (intervention or placebo) among the patients with less severe lesions. In contrast, Wong et al. (2004) grouped chronic atrophic gastritis with the precancerous lesions and found that $H$. pylori eradication was effective only among patients with less severe lesions (see Table 3-1).

The additional four trials of primary prevention, two in China (Wong et al. 2012; Zhou et al. 2014) and one each in Colombia (Correa et al. 2000) and Japan (Saito et al. 2005), had a combined total of 10 gastric cancer cases in the intervention groups and 13 in the placebo groups. Two smaller studies lacked sufficient statistical power to evaluate gastric cancer 
incidence, but reported that $H$. pylori treatment was effective in promoting the regression of histological gastric lesions (Correa et al. 2000; Zhou et al. 2014). Wong et al. (2012) did not evaluate the effect of treatment on gastric cancer incidence, because seven of the nine cancer cases (across several treatment options, such as COX 2 inhibitor treatment) occurred during the treatment period.

When all six randomized controlled trials of primary prevention were included in a metaanalysis, the risk ratio was $0.66(95 \% \mathrm{CI}=0.46$ to 0.95$)$, indicating a beneficial effect of H. pylori eradication therapy (Ford et al. 2014). It should be noted that these results were heavily weighted by the results in the Shandong Intervention Trial. Ford et al. (2014) also conducted a meta-analysis evaluating cancer mortality and found a non-statistically significant decrease in mortality in the intervention group $(\mathrm{RR}=0.67,95 \% \mathrm{CI}=0.40$ to 1.11$)$; the analysis included 24 deaths in the intervention groups and 36 in the placebo groups (Ford et al. 2014).

Three trials evaluating prevention of metachronous gastric cancer or "secondary prevention" (in Japan and South Korea) found a lower risk of new cancer in the H. pylori intervention group than in the control group (Choi et al. 2018; Choi et al. 2014b; Fukase et al. 2008). The findings were statistically significant in the Japanese study and in the Choi et al. (2018) study (see Table 3-1); additionally, when the results of the two earliest studies (Choi et al. 2014b; Fukase et al. 2008) were combined in a meta-analysis, a protective effect of eradication therapy was seen $(\mathrm{RR}=0.47,95 \% \mathrm{CI}=0.28$ to 0.80$)$ (Wald 2014).

Meta-analyses that pooled the results of cohort studies or of cohort studies and randomized controlled trials combined found results similar to those of the meta-analyses of the trials. An analysis of eight primary-prevention cohort studies reported a relative risk of $0.46(95 \%$ $\mathrm{CI}=0.32$ to 0.66 ) (Doorakkers et al. 2016). A meta-analysis of both trials and cohort studies found relative risks of $0.62(95 \% \mathrm{CI}=0.49$ to 0.79$)$ for primary prevention (six trials and eight cohorts) and $0.46(95 \% \mathrm{CI}=0.35$ to 0.60$)$ for secondary prevention of metachronous gastric cancer (two trials and eight cohorts) (Lee et al. 2016). Another secondary-prevention metaanalysis (Yoon et al. 2014) found a relative risk of $0.42(95 \% \mathrm{CI}=0.32$ to 0.56$)$ in a pooled analysis of 13 trials or cohort studies. Additional meta-analyses that combined both primary- and secondary-prevention studies (Chen et al. 2016; Hernández et al. 2014; Lee et al. 2016) were considered to be less informative. The results of these meta-analyses are summarized in Table 3-2. Other meta-analysis publications were identified but are not included in Table 3-2 because they included multiple publications of the same study in the analysis or included studies that did not evaluate efficacy or effectiveness in cancer prevention. 
Table 3-2. Meta-analyses of Randomized Controlled Trials and Cohort Studies Investigating the Effectiveness of $\boldsymbol{H}$. pylori Eradication in Reducing Gastric Cancer Incidence

\begin{tabular}{|c|c|c|c|c|}
\hline Reference & $\begin{array}{l}\text { Type of Study } \\
\text { (No. of Studies) }\end{array}$ & $\begin{array}{l}\text { Exposure Group } \\
\text { (No. of Studies) }\end{array}$ & Risk Estimate & Heterogeneity \\
\hline \multicolumn{5}{|c|}{ Studies on individuals without gastric cancer } \\
\hline \multirow[t]{7}{*}{ Ford et al. (2014) } & \multirow[t]{7}{*}{ Trial (6) } & Type of outcome & & \\
\hline & & Incidence (6) & $0.66(0.46-0.95)$ & $I^{2}=0 \% ; p=0.60$ \\
\hline & & Mortality (3) & $0.67(0.40-1.11)$ & $\mathrm{I}^{2}=0 \% ; \mathrm{p}=0.90$ \\
\hline & & Pre-neoplastic lesions present & & \\
\hline & & No (2) & $0.42(0.02-7.69)$ & \\
\hline & & Yes (4) & $0.86(0.47-1.59)$ & \\
\hline & & Mixed (2) & $0.38(0.12-1.23)$ & \\
\hline \multirow{2}{*}{$\begin{array}{l}\text { Doorakkers et al. } \\
(2016)\end{array}$} & \multirow[t]{2}{*}{ Cohort (8) } & Overall analysis & $0.46(0.32-0.66)$ & $\mathrm{I}^{2}=32.3 \% ; \mathrm{p}=0.17$ \\
\hline & & $\begin{array}{l}\text { Adjusted for follow-up and } \\
\text { confounding (4) }\end{array}$ & $0.46(0.29-0.72)$ & $\mathrm{I}^{2}=44.4 \% ; \mathrm{p}=0.15$ \\
\hline \multicolumn{5}{|c|}{ Studies on gastric cancer patients ${ }^{\mathrm{a}}$} \\
\hline \multirow[t]{3}{*}{ Yoon et al. $(2014)^{b}$} & Trial (2) & Trial and prospective cohort (3) & $0.39(0.20-0.75)$ & $\mathrm{I}^{2}=24.7 \% ; \mathrm{p}=0.27$ \\
\hline & Cohort (8) & & & Outcome is \\
\hline & $\begin{array}{l}\text { Other } \\
\text { observational (2) }\end{array}$ & & & $\begin{array}{l}\text { metachronous gastric } \\
\text { cancer }\end{array}$ \\
\hline \multicolumn{5}{|c|}{ Combined studies of cancer and cancer-free patients } \\
\hline \multirow[t]{4}{*}{ Chen et al. (2016) } & Trial (8) & All studies & $0.64(0.48-0.85)$ & $\mathrm{I}^{2}=32.3 \% ; \mathrm{p}=0.93$ \\
\hline & & Baseline diagnosis & & \\
\hline & & Non-atrophic gastritis/gastritis & $0.25(0.08-0.81)$ & \\
\hline & & IM/DYS & $0.88(0.59-1.31)$ & \\
\hline Hernández et al. (2014) & Trial (7) & Overall five studies & $0.57(0.42-0.79)$ & $\mathrm{I}^{2}=0 \% ; \mathrm{p}=0.48^{\mathrm{c}}$ \\
\hline \multirow[t]{9}{*}{ Lee et al. (2016) } & Trial (8) & All studies & $0.54(0.46-0.65)$ & $\mathrm{I}^{2}=0.0 \% ; \mathrm{p}=0.67$ \\
\hline & Cohort (16) & Trial & $0.60(0.44-0.81)$ & \\
\hline & & Cohort & $0.52(0.41-0.64)$ & \\
\hline & & Primary intervention & $0.62(0.49-0.79)$ & \\
\hline & & Secondary intervention & $0.46(0.35-0.60)$ & \\
\hline & & $\begin{array}{l}\text { Baseline incidence of gastric cancer } \\
\text { (tertiles) }\end{array}$ & & \\
\hline & & Lowest & $0.80(0.56-1.15)$ & \\
\hline & & Middle & $0.49(0.38-0.64)$ & \\
\hline & & Highest & $0.45(0.32-0.64)$ & \\
\hline
\end{tabular}

$\mathrm{CAG}=$ chronic atrophic gastritis; DYS = dysplasia; IM = intestinal metaplasia.

aPatients with previous endoscopic resection of early gastric cancer.

${ }^{b}$ Because the meta-analysis of all studies included those that were not analytic studies, the results of that analysis are not included in the table.

'Does not include Wong et al. (2012), Saito et al. (2005), or Choi et al. (2014b). 
Several additional planned or ongoing studies will investigate the efficacy of $H$. pylori eradication in reducing the incidence of gastric cancer. A large-scale study in Baltic and Eastern European countries (the GISTAR study), which has recently begun recruitment, aims to recruit 30,000 men and women aged 40 to 64 and follow them for 15 years (Leja et al. 2017; Leja et al. 2014). A study in South Korea that has also recently begun recruitment plans to recruit 11,000 men and women aged 40 to 65 who are invited to participate in the national gastric cancer screening program. Those found to be infected with $H$. pylori will be randomized into the eradication study and followed for at least 10 years (Choi et al. 2014a; Park et al. 2017). A third ongoing study in the United Kingdom (the H. pylori Screening Study) recruited participants between 1997 and 2006. Although this is not an eradication study, those screened for H. pylori who tested positive were treated. All participants will be followed for 15 to 20 years (Wald 2014). Although not a placebo-controlled trial, a large study in China will compare a high-dose treatment with a low-dose treatment in 180,000 participants followed for at least 7 years. Initial eradication rates in the high-dose group were approximately 73\% (Pan et al. 2016).

\section{Gastric MALT Lymphoma}

Because MALT lymphoma is a rare cancer, no randomized controlled trials have assessed the efficacy of $H$. pylori eradication therapy for its prevention and treatment; however, efficacy has been assessed in numerous observational studies. In a meta-analysis of 32 observational studies with 1,408 gastric MALT lymphoma patients, Zullo et al. (2009) found that $H$. pylori eradication treatment resulted in an overall remission rate of $77.5 \%(95 \% \mathrm{CI}=75.3 \%$ to $79.7 \%)$. Remission rates were higher for Stage 1 than Stage 2 lymphoma (75.3\% vs. 55.6\%), but treatment was effective at both cancer stages. Median follow-up times for these studies ranged from 1 to 5 years. Recently, long-term follow-up studies of gastric MALT lymphoma patients receiving H. pylori eradication therapy have shown remission in up to $80 \%$ of cases, with $80 \%$ of these individuals remaining disease-free after 10 years (Fischbach 2014; Wündisch et al. 2012).

\subsubsection{Cost-benefit Analyses Studies}

Numerous economic models in numerous geographic locations, including both low- and highprevalence countries, have been published that evaluated whether $H$. pylori screening and treatment are cost-effective measures for the prevention of stomach cancer in a variety of populations. Two systematic reviews published in 2013 (Areia et al. 2013; Lansdorp-Vogelaar and Sharp 2013) reviewed 12 cost-effectiveness studies on H. pylori screening and treatment in the general population, including four studies each from North America, Europe, and Asia. Areia et al. (2013) also reviewed one South Korean cost-effectiveness study on H. pylori eradication after endoscopic removal of gastric cancer. The IARC working group on $H$. pylori eradication reviewed nine economic studies (Moayyedi 2014). Several new cost-effectiveness studies of screening and treatment have been published since these 2013 reviews. These newer studies were conducted in the United States (Yeh et al. 2016), Australia (Schulz et al. 2014), New Zealand (Teng et al. 2017), Taiwan (Cheng et al. 2015), and Hong Kong (Wong et al. 2014). Studies found $H$. pylori screening and treatment to be cost-effective based on a threshold of $\$ 50,000$ per life-year saved, especially for high-risk populations. Importantly, the findings in many studies were robust to differences in $\mathrm{H}$. pylori prevalence and patient gender and ethnicity (LansdorpVogelaar and Sharp 2013). Most studies assumed 30\% effectiveness of H. pylori eradication in reducing gastric cancer incidence; however, sensitivity analyses found that $H$. pylori eradication 
would still be cost-effective if the effectiveness of $H$. pylori eradication in reducing stomach cancer incidence were as low as 15\% (Lansdorp-Vogelaar and Sharp 2013).

Factors that may influence the cost-effectiveness of $H$. pylori screening and treatment include screening methods, type of $H$. pylori therapy, and population characteristics such as age, race, or ethnicity, migrant status, and geographic region. Most general-population studies in both highand low-prevalence countries evaluated serology screening (the most available test) and found it to be cost-effective [reviewed by Areia et al. (2013); Cheng et al. (2015); Lansdorp-Vogelaar and Sharp (2013); Teng et al. (2017); Wong et al. (2014); Yeh et al. (2016)]. However, some studies reported that the stool antigen screening method, which has greater sensitivity and specificity, was more cost-effective than either serology or urea breath test screening [Xie et al. (2009), as cited by Areia et al. (2013); Schulz et al. (2014)]. Most cost-effectiveness studies considered only the standard PPI triple therapy; however, one study evaluated the bismuth-containing quadruple therapy and found it to be cost-effective as well [Xie et al. (2009), as cited by Moayyedi (2014)].

Population characteristics were also considered in the economic models. The overall conclusion of Areia et al. (2013) was that screening at or above age 50 was the most cost-effective;

however, several Asian studies concluded that screening beginning at age 30 would be the most cost-effective [Cheng et al. (2015); Lee et al. (2007); and Yeh et al. (2009), as cited by Areia et al. (2013)]. The effect of age may depend on the population; for example, Teng et al. (2017) found that cost-effectiveness was highest for Māori participants aged 45 to 49 and non-Māori participants aged 60 to 64. A study in Australia (Schulz et al. 2014) found screening and treatment of immigrants and refugees from high-prevalence countries to be cost-effective, and concluded that it may be an effective strategy for reducing stomach cancer in these populations.

In an overview of 10 cost-effectiveness or cost-utility studies, Lansdorp-Vogelaar and Sharp (2013) concluded $H$. pylori screening and treatment was cost-effective, coming in well below the threshold of $\$ 50,000$ per life-year saved for the general population. In other, more recent, studies screening and treatment were found to be cost-effective only in populations at high-risk for gastric cancer, such as indigenous populations (Teng et al. 2017), or a subset of those at high risk, such as smokers (Yeh et al. 2016). In H. pylori high-prevalence countries, estimated costs ranged from $\$ 200$ to $\$ 17,000$ per life-year saved. The studies with the lowest assumed H. pylori prevalence had the highest cost per life-year saved, but eradication was still cost-effective. Likewise, studies reporting cost-effectiveness in low-prevalence countries also found screening and treatment to be cost-effective, ranging from $\$ 10,000$ to $\$ 35,000$ per life-year saved. While the cost-effectiveness estimates were, on average, higher in low-prevalence countries, they were still well below the threshold estimates (Lansdorp-Vogelaar and Sharp 2013).

In many of these studies, the cost-effectiveness threshold analyses considered only stomach cancer, and did not take into account the additional potential savings from $H$. pylori screening and treatment that could result from decreases in dyspepsia, ulcers, and other $H$. pylori-related disorders. The analyses also did not take into account the potential detrimental effects of increased antibiotic resistance or the potential reinfection rates, which have not been well studied (Hu et al. 2017; Lansdorp-Vogelaar and Sharp 2013). The IARC working group (IARC 2014) recommended that further studies should evaluate benefits using quality-adjusted life-years rather than life-years saved (Lansdorp-Vogelaar and Sharp 2013; Moayyedi 2014). Additional 
economic cost-benefit analyses are needed from randomized controlled trials, especially in areas where the eradication programs are most likely to be implemented first.

\subsubsection{Issues and Concerns}

Although the potential for $H$. pylori eradication to prevent $30 \%$ to $40 \%$ of new cases of noncardia gastric cancer has been demonstrated, no large-scale $H$. pylori eradication programs have been implemented; however, a few smaller, targeted eradication programs have been implemented regionally (see Section 3.2.2). This caution is partially due to concern about unintended consequences of such programs. Three major concerns about $H$. pylori eradication are the potential for increased bacterial resistance to antibiotics, a negative impact on the normal gastrointestinal flora found in the body, and the likelihood of reinfection with $H$. pylori after treatment. These concerns are compounded by the fact that many of the antibiotics used to treat H. pylori infection are commonly used to treat other serious infections. A recent European consensus report cautioned that use of commonly used antibiotics could create additional resistance selection on pathogens other than H. pylori (Malfertheiner et al. 2017). In addition, evidence suggests an inverse relationship between $H$. pylori infection and GERD and its complications, including Barrett's esophagus and esophageal adenocarcinoma [reviewed by Derakhshan et al. (2016); Parsonnet (2014)]. However, eradication does not appear to worsen pre-existing GERD (Zagari et al. 2015).

Reinfection with $H$. pylori has been observed to occur in more than $10 \%$ of those who were successfully treated in high prevalence areas, and reinfection rates increased as time since treatment increased (Hu et al. 2017; Morgan et al. 2013). In a recent review (Hu et al. 2017), reinfection rates ranged from $3.1 \%$ in countries with a very high human development index (HDI) to $11 \%$ in countries with a low HDI. Factors associated with reinfection included socioeconomic and sanitary conditions, as well as treatment adherence and study site, which was likely associated with regional antibiotic resistance, which suggests that recrudescence is a component of 1-year recurrence rates in many populations (Hu et al. 2017; Morgan et al. 2013).

Any eradication efforts should be tailored to the specific geographic area and target population, to guide the selection of appropriate antibiotic therapy and to develop better methods of treatment (Thung et al. 2016). All randomized controlled trials of eradication published to date were conducted in high-prevalence countries. However, both the short- and long-term effects of treatment programs will differ between regions with differing prevalence levels. Factors to consider in $H$. pylori eradication include the prevalence of $H$. pylori in the population, identification of the most appropriate population for screening (the general population or those showing symptoms of disease), the best age at which to begin screening, and the stage of disease at which eradication would be most effective. In high-prevalence regions, screening and treatment of the general population may be indicated, whereas in lower-prevalence countries with low-to-moderate risk of gastric cancer, integration of screening into existing prevention methods (such as colonoscopy screening) or screening those who show symptoms may be more effective (Lee et al. 2007). The optimal age for general screening and treatment programs may vary based on the prevalence of $H$. pylori in the population, and age should be taken into account (as discussed in Section 3.1.2).

The effectiveness of $H$. pylori eradication therapy in the prevention of stomach cancer may depend on the presence and severity of atrophic damage at the time of eradication (Sugano et al. 
2015). H. pylori eradication therapy diminishes the inflammatory response and early treatment can help prevent the appearance of preneoplastic lesions. The optimal timing for stomach-cancer prevention may be before these preneoplastic conditions appear (Malfertheiner et al. 2017); however, $\mathrm{H}$. pylori eradication may offer some benefits by reducing risk in the presence of preneoplastic conditions (Coelho et al. 2013; Malfertheiner et al. 2017). As mentioned in Section 3.1.2, the largest randomized controlled trial found that $H$. pylori eradication was effective in reducing cancer incidence among participants with precancerous lesions at baseline (Li et al. 2014).

\subsection{Policies and Recommendations}

Even though $H$. pylori is a treatable infection, and stomach cancer is one of the leading causes of cancer death worldwide, few national efforts at screening and prevention have been made (Section 3.2.2). There have been, however, numerous national and regional consensus statements on $\mathrm{H}$. pylori screening and treatment in the prevention of $\mathrm{H}$. pylori-induced cancer (Section 3.2.1).

\subsubsection{National Consensus Recommendations for the Prevention of H. pylori-induced Cancer}

Over the last 5 years, numerous publications have reported on national and regional consensus statements on $\mathrm{H}$. pylori management. Typically, these statements are the result of a workshop of international, national, or regional experts who are charged with (1) reviewing the clinical and other relevant studies related to $H$. pylori management (e.g., diagnosis, treatment, and prevention) and (2) voting on the level of evidence (a grade reached according to specific guidelines) and the strength of recommendations for specific statements. Recommendations relevant to the prevention and treatment of $H$. pylori-induced cancer are summarized in Table 3-3. (Not included in the table are other recommendations, such as those for diagnosis and type of treatment.) 
Table 3-3. Recommendations for Prevention of $\boldsymbol{H}$. pylori-induced Cancer

\begin{tabular}{|c|c|c|c|}
\hline $\begin{array}{l}\text { Type of } \\
\text { Recommendation }\end{array}$ & Population & Strength of the Association/Region & References \\
\hline \multirow[t]{3}{*}{ Screen and treat } & General population & $\begin{array}{l}\text { Strong: Should be considered for } \\
\text { those under } 35 \text { : Brazil (Third } \\
\text { Brazilian Consensus) }\end{array}$ & Coelho et al. (2013) \\
\hline & & $\begin{array}{l}\text { Insufficient: Chile (Chilean Society of } \\
\text { Gastroenterology) }\end{array}$ & Torres et al. (2016) \\
\hline & & $\begin{array}{l}\text { Weak: Asia (10 ASEAN countries); } \\
\text { Bangkok Report) (Community } \\
\text { screening) }\end{array}$ & Mahachai et al. (2018) \\
\hline \multirow[t]{5}{*}{ Screen and treat } & $\begin{array}{l}\text { Communities or } \\
\text { individuals with a }\end{array}$ & Stronga: & \\
\hline & $\begin{array}{l}\text { high risk of gastric } \\
\text { cancer }\end{array}$ & $\begin{array}{l}\text { Europe (Maastricht V/Florence } \\
\text { Consensus Report 20) }\end{array}$ & Malfertheiner et al. (2017) \\
\hline & & $\begin{array}{l}\text { Italy (II Working Group Consensus } \\
\text { Report) }{ }^{\mathrm{b}}\end{array}$ & Zagari et al. (2015) \\
\hline & & $\begin{array}{l}\text { Moderate } \text { : Taiwan (Convened by the } \\
\text { Steering Committee) }\end{array}$ & Sheu et al. (2017) \\
\hline & & Need more research: Chile & Torres et al. (2016) \\
\hline \multirow[t]{2}{*}{ Screen and treat } & $\begin{array}{l}\text { Populations with } \\
\text { low and/or } \\
\text { intermediate gastric }\end{array}$ & $\begin{array}{l}\text { Moderate } \text { : Taiwan (intermediate risk } \\
\text { only) }\end{array}$ & Sheu et al. (2017) \\
\hline & cancer risk & Weak recommendation: Europe & Malfertheiner et al. (2017) \\
\hline \multirow[t]{2}{*}{ Screen and treat } & $\begin{array}{l}\text { Individuals with } \\
\text { family history of } \\
\text { gastric cancer (e.g., } \\
\text { first-degree relatives } \\
\text { of gastric cancer } \\
\text { patients) }\end{array}$ & $\begin{array}{l}\text { Strong or recommended: } 10 \text { ASEAN } \\
\text { countries, Italy }{ }^{\text {, Brazil, China }} \\
\text { (Chinese Society of } \\
\text { Gastroenterology), South Korea } \\
\text { (Korean College of Helicobacter and } \\
\text { Upper Gastrointestinal Research } \\
\text { Guideline Steering Committee) }\end{array}$ & $\begin{array}{l}\text { Coelho et al. (2013); Lee } \\
\text { (2014a); Mahachai et al. } \\
\text { (2018); Zagari et al. (2015) }\end{array}$ \\
\hline & & Insufficient: United States & Chey et al. (2017) \\
\hline Screen and treat & $\begin{array}{l}\text { Immigrants from } \\
\text { high-risk regions }\end{array}$ & $\begin{array}{l}\text { Recommended: Canada (Canadian } \\
\text { Helicobacter Study Group and } \\
\text { Canadian Cancer Society) }\end{array}$ & $\begin{array}{l}\text { Taylor et al. (2014) [cites CCS } \\
\text { (2014)] }\end{array}$ \\
\hline \multirow[t]{3}{*}{ Screen and treat } & $\begin{array}{l}\text { Patients with } \\
\text { symptoms of gastric } \\
\text { diseases }\end{array}$ & $\begin{array}{l}\text { Strong or recommended: Italy, China, } \\
\text { South Korea }\end{array}$ & $\begin{array}{l}\text { Lee (2014a); Zagari et al. } \\
(2015)\end{array}$ \\
\hline & & Moderate: Brazil & Coelho et al. (2013) \\
\hline & & Insufficient: United States & Chey et al. (2017) \\
\hline
\end{tabular}




\begin{tabular}{|c|c|c|c|}
\hline $\begin{array}{c}\text { Type of } \\
\text { Recommendation }\end{array}$ & Population & Strength of the Association/Region & References \\
\hline \multirow[t]{4}{*}{ Screen and treat } & $\begin{array}{l}\text { Patients with } \\
\text { precancerous gastric }\end{array}$ & Strong: 10 ASEAN countries & Mahachai et al. (2018) \\
\hline & lesions & Moderate: Brazil & Coelho et al. (2013) \\
\hline & & "Favors": Chile & Torres et al. (2016) \\
\hline & & Weak: South Korea & Choi (2013) \\
\hline $\begin{array}{l}\text { Treatment of } \\
\text { cancer }\end{array}$ & $\begin{array}{l}\text { Patients with gastric } \\
\text { MALT lymphoma }\end{array}$ & $\begin{array}{l}\text { Strong or recommended: } 10 \text { ASEAN } \\
\text { countries, Taiwan, China, South } \\
\text { Korea, Japan, United States }\end{array}$ & $\begin{array}{l}\text { Chey et al. (2017); Lee } \\
\text { (2014a); Mahachai et al. } \\
\text { (2018); Sheu et al. (2017) }\end{array}$ \\
\hline $\begin{array}{l}\text { Secondary } \\
\text { prevention and/or } \\
\text { treatment of cancer }\end{array}$ & $\begin{array}{l}\text { Patients with gastric } \\
\text { cancer }\end{array}$ & $\begin{array}{l}\text { Strong or recommended: Italy, Chile, } \\
\text { China, South Korea, Japan, United } \\
\text { States }\end{array}$ & $\begin{array}{l}\text { Chey et al. (2017); Lee } \\
\text { (2014a); Torres et al. (2016); } \\
\text { Zagari et al. (2015) }\end{array}$ \\
\hline
\end{tabular}

ASEAN = Association of Southeast Asian Nations. The 10 members are Brunei Darussalam, Cambodia, Indonesia, Laos, Malaysia, Myanmar, Philippines, Singapore, Thailand, and Vietnam.

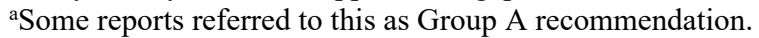

bStatement was "that the recommendation should be considered."

'Some reports referred to this as Group B recommendation.

Overall, there was consensus across the working groups that $H$. pylori eradication could reduce but not completely eliminate $H$. pylori-induced cancer. Most, but not all, working groups recommended screening and treatment programs for individuals with a high risk of non-cardia gastric cancer (including those with a family history of non-cardia gastric cancer or immigrants from high-risk regions); however, working groups from some countries (such as the United States and Chile) thought more research was needed. Some working groups recommended that screening and treatment programs include patients without advanced gastric lesions, and other groups (e.g., South Korea) recommended treatment of patients with intestinal metaplasia. Most groups recommended that the cancer-treatment program treat $H$. pylori among patients with gastric MALT lymphoma as well as non-cardia gastric cancer. One working group has recommended against general screening and treatment in children and adolescents; but it recommended that those with gastric or duodenal ulcers should be treated with a regimen tailored to the child or adolescent (Jones et al. 2017) The groups also recommended that endoscopic or histological surveillance may be needed after treatment (Lee et al. 2007; Sheu et al. 2017).

\subsubsection{Screening and Treatment Programs}

Worldwide, only a few countries have instituted gastric cancer prevention programs, either regionally or nationwide, and only some of these include $H$. pylori screening and treatment. The majority of these programs are in Asia. In Japan, which has high rates of stomach cancer, but also one of the highest 5-year survival rates, at 90\% (Asaka 2014), an early stomach-cancer detection screening program using indirect barium contrast imaging has been in place for many years, although participation rates have been low. In 2013, after a successful trial showed that eradicating $H$. pylori reduced the incidence of secondary non-cardia gastric cancer, Japan approved national health insurance coverage of $H$. pylori eradication therapy for all patients with gastric MALT lymphoma, early non-cardia gastric cancer, idiopathic thrombocytopenia purpura, gastric and duodenal ulcers, and chronic gastritis, who are diagnosed via endoscopic examination. In South Korea, a national program was begun in the early 2000s to provide 
stomach-cancer screening every 2 years for all residents aged 40 and over. Participation rates have increased each year; in 2011, about half of those eligible were screened (Suh et al. 2013).

In 2006, Chile became the first Latin American country to institute a program that provides stomach-cancer screening to symptomatic people aged 40 and over. The program provides endoscopic examination for H. pylori detection, biopsy, and treatment (Ferreccio 2014). This program has had limited success, as population coverage has been small (Torres et al. 2016). The program is currently under review, and other strategies are being considered, including generalpopulation screening and eradication in high-risk populations, accompanied by more efficient early-detection methods.

While most current gastric cancer prevention programs are symptoms based and include endoscopy or imaging as the primary screening for gastric cancer, several smaller scale efforts in Taiwan have included a general-population stomach-cancer prevention program combining H. pylori screening and endoscopy to older populations considered to be at highest risk for gastric cancer. The first program was pilot-tested on Matsu Island, a high-risk population, with promising results (Lee et al. 2013; Lee and Lin 2017). Based on these results, two additional regions of Taiwan have implemented a similar program combining the urea breath test for H. pylori and endoscopic screening for stomach cancer among those aged 50 to 69 (Lee 2014b). Another region in Taiwan is conducting a large-scale randomized controlled trial that combines colon-cancer screening with $H$. pylori screening, with treatment for those who test positive (Lee and Lin 2017).

\subsection{Summary of the Recommendations of International Expert Working Groups (Including the IARC Working Group)}

Given the strong link between $H$. pylori and non-cardia gastric cancer, as well as the high global burden of disease, international expert working groups have recommended that countries worldwide should devote additional public health resources to this disease. This global burden and the feasibility of treating the main cause of disease make $H$. pylori a possible target for intervention. Recent randomized trials have provided support for $H$. pylori eradication in the prevention of stomach cancer, while economic analyses have shown it to be cost-effective in many populations, particularly high-risk populations. Several additional large, randomized trials currently under way may add to the evidence. As well as preventing non-cardia gastric cancer (and gastric MALT lymphoma), H. pylori eradication may also prevent diseases such as dyspepsia and peptic ulcers, increasing its cost-effectiveness.

Although evidence for the effectiveness of screening and treatment in reducing stomach-cancer incidence is increasing, caution should be exercised in any planned intervention program. Local antibiotic resistance patterns should be taken into account in the choice of treatment method, as well as in targeting of the appropriate populations for intervention. Other potential consequences of eradication therapy must also be considered in any program, including increases in antibiotic resistance, changes in the natural gastrointestinal flora, and increases in diseases on which H. pylori may have a beneficial effect, such as GERD and esophageal cancer. Before implementation, any planned programs should consider objective assessments of feasibility, effectiveness, program acceptance, cost-effectiveness, and adverse consequences relevant to the local area. 


\section{References}

AlMalki AS. 2008. Helicobacter pylori eradication in nonulcer dyspepsia: Does it really matter? Saudi J Gastroenterol. 14(2):93-95. http://dx.doi.org/10.4103/1319-3767.39628

Anderson WF, Rabkin CS, Turner N, Fraumeni JF, Jr., Rosenberg PS, Camargo MC. 2018. The changing face of noncardia gastric cancer incidence among US non-Hispanic whites. J Natl Cancer Inst. 110(6):1-8. http://dx.doi.org/10.1093/jnci/djx262

Areia M, Carvalho R, Cadime AT, Rocha Goncalves F, Dinis-Ribeiro M. 2013. Screening for gastric cancer and surveillance of premalignant lesions: A systematic review of costeffectiveness studies. Helicobacter. 18(5):325-337. http://dx.doi.org/10.1111/hel.12050

Asaka M. 2014. Chapter 1.2. Strategy to eliminate gastric cancer deaths in Japan. In: Helicobacter pylori Eradication as a Strategy for Preventing Gastric Cancer. Lyon, France: International Agency for Research on Cancer. p. 21-27.

Aziz RK, Khalifa MM, Sharaf RR. 2015. Contaminated water as a source of Helicobacter pylori infection: A review. J Adv Res. 6(4):539-547. http://dx.doi.org/10.1016/j.jare.2013.07.007

Balakrishnan M, George R, Sharma A, Graham DY. 2017. Changing trends in stomach cancer throughout the world. Curr Gastroenterol Rep. 19(8):36. http://dx.doi.org/10.1007/s11894-017$\underline{0575-8}$

Biranjia-Hurdoyal SD, Seetulsingh-Goorah SP. 2016. Performances of four Helicobacter pylori serological detection kits using stool antigen test as gold standard. PLoS One. 11(10):e0163834. http://dx.doi.org/10.1371/journal.pone.0163834

Bjorkman DJ. 2017. Racial and ethnic disparities in gastric cancer risk. NEJM Journal Watch. https://production.jwatch.org/na43129/2017/01/17/racial-and-ethnic-disparities-gastric-cancerrisk. [Accessed on March 14, 2018]

Blase JL, Campbell PT, Gapstur SM, Pawlita M, Michel A, Waterboer T, Teras LR. 2016. Prediagnostic Helicobacter pylori antibodies and colorectal cancer risk in an elderly, Caucasian population. Helicobacter. 21(6):488-492. http://dx.doi.org/10.1111/hel.12305

Bui D, Brown HE, Harris RB, Oren E. 2016. Serologic evidence for fecal-oral transmission of Helicobacter pylori. Am J Trop Med Hyg. 94(1):82-88. http://dx.doi.org/10.4269/ajtmh.15-0297

Camargo MC, Yepez MC, Ceron C, Guerrero N, Bravo LE, Correa P, Fontham ET. 2004. Age at acquisition of Helicobacter pylori infection: Comparison of two areas with contrasting risk of gastric cancer. Helicobacter. 9(3):262-270. http://dx.doi.org/10.1111/j.1083-4389.2004.00221.x

Canadian Cancer Society (CCS). 2014. Helicobacter pylori (H. pylori). Canadian Cancer Society. https://www.cancer.ca/en/cancer-information. [Retrieved on July 30, 2014]

Cavaleiro-Pinto M, Peleteiro B, Lunet N, Barros H. 2011. Helicobacter pylori infection and gastric cardia cancer: Systematic review and meta-analysis. Cancer Causes Control. 22(3):375387. http://dx.doi.org/10.1007/s10552-010-9707-2 
Centers for Disease Control and Prevention (CDC). 2016. List of vaccines used in United States. Atlanta, GA: Centers for Disease Control and Prevention.

https://www.cdc.gov/vaccines/vpd/vaccines-list.html. [Last updated: November 22, 2016]

Chen XZ, Schöttker B, Castro FA, Chen H, Zhang Y, Holleczek B, Brenner H. 2016.

Association of Helicobacter pylori infection and chronic atrophic gastritis with risk of colonic, pancreatic and gastric cancer: A ten-year follow-up of the ESTHER cohort study. Oncotarget. 7(13):17182-17193. http://dx.doi.org/10.18632/oncotarget.7946

Cheng HC, Wang JD, Chen WY, Chen CW, Chang SC, Sheu BS. 2015. Helicobacter pylori testand-treat program can be cost-effective to prevent gastric cancer in Taiwanese adults: Referred to the nationwide reimbursement database. Helicobacter. 20(2):114-124.

http://dx.doi.org/10.1111/hel.12185

Chey WD, Leontiadis GI, Howden CW, Moss SF. 2017. ACG Clinical Guideline: Treatment of Helicobacter pylori infection. Am J Gastroenterol. 112(2):212-239.

http://dx.doi.org/10.1038/ajg.2016.563

Choi IJ. 2013. Current evidence of effects of Helicobacter pylori eradication on prevention of gastric cancer. Korean J Intern Med. 28(5):525-537.

Choi IJ, Kook MC, Kim YI, Cho SJ, Lee JY, Kim CG, Park B, Nam BH. 2018. Helicobacter pylori therapy for the prevention of metachronous gastric cancer. N Engl J Med. 378(12):10851095. http://dx.doi.org/10.1056/NEJMoa1708423

Choi IJ, Park JY, Herrero R. 2014a. Chapter 4.3. Effect of Helicobacter pylori eradication on gastric cancer prevention in the Republic of Korea: A randomized controlled clinical trial. In: Helicobacter pylori Eradication as a Strategy for Preventing Gastric Cancer. Lyon, France: International Agency for Research on Cancer. p. 154-160.

Choi J, Kim SG, Yoon H, Im JP, Kim JS, Kim WH, Jung HC. 2014b. Eradication of Helicobacter pylori after endoscopic resection of gastric tumors does not reduce incidence of metachronous gastric carcinoma. Clin Gastroenterol Hepatol. 12(5):793-800. http://dx.doi.org/10.1016/j.cgh.2013.09.057

Coelho LG, Maguinilk I, Zaterka S, Parente JM, Passos MCF, Moraes-Filho JPP. 2013. 3rd Brazilian consensus on Helicobacter pylori. Arq Gastroenterol. 50(2):1-17. http://dx.doi.org/10.1590/S0004-28032013005000001

Colquhoun A, Arnold M, Ferlay J, Goodman KJ, Forman D, Soerjomataram I. 2015. Global patterns of cardia and non-cardia gastric cancer incidence in 2012. Gut. 64(12):1881-1888. http://dx.doi.org/10.1136/gutjnl-2014-308915

Conteduca V, Sansonno D, Lauletta G, Russi S, Ingravallo G, Dammacco F. 2013. H. pylori infection and gastric cancer: State of the art (review). Int J Oncol. 42(1):5-18. http://dx.doi.org/10.3892/ijo.2012.1701

Correa P, Fontham ET, Bravo JC, Bravo LE, Ruiz B, Zarama G, Realpe JL, Malcom GT, Li D, Johnson WD et al. 2000. Chemoprevention of gastric dysplasia: Randomized trial of antioxidant 
supplements and anti-Helicobacter pylori therapy. J Natl Cancer Inst. 92(23):1881-1888. http://dx.doi.org/10.1093/jnci/92.23.1881

Cover TL. 2016. Helicobacter pylori diversity and gastric cancer risk. MBio. 7(1):e01869-01815. http://dx.doi.org/10.1128/mBio.01869-15

de Martel C, Ferlay J, Franceschi S, Vignat J, Bray F, Forman D, Plummer M. 2012. Global burden of cancers attributable to infections in 2008: A review and synthetic analysis. Lancet Oncol. 13(6):607-615. http://dx.doi.org/10.1016/S1470-2045(12)70137-7

de Sanjose S, Dickie A, Alvaro T, Romagosa V, Garcia Villanueva M, Domingo-Domenech E, Fernandez de Sevilla A, El-Omar E. 2004. Helicobacter pylori and malignant lymphoma in Spain. Cancer Epidemiol Biomarkers Prev. 13(6):944-948.

Derakhshan MH, Arnold M, Brewster DH, Going JJ, Mitchell DR, Forman D, McColl KE. 2016. Worldwide inverse association between gastric cancer and esophageal adenocarcinoma suggesting a common environmental factor exerting opposing effects. Am J Gastroenterol. 111(2):228-239. http://dx.doi.org/10.1038/ajg.2015.405

Diaconu S, Predescu A, Moldoveanu A, Pop CS, Fierbinteanu-Braticevici C. 2017. Helicobacter pylori infection: Old and new. J Med Life. 10(2):112-117.

Doorakkers E, Lagergren J, Engstrand L, Brusselaers N. 2016. Eradication of Helicobacter pylori and gastric cancer: A systematic review and meta-analysis of cohort studies. J Natl Cancer Inst. 108(9). http://dx.doi.org/10.1093/jnci/djw132

Dore MP, Pes GM, Bassotti G, Usai-Satta P. 2016. Dyspepsia: When and how to test for Helicobacter pylori infection. Gastroenterol Res Pract. 2016:8463614.

http://dx.doi.org/10.1155/2016/8463614

Epplein M, Pawlita M, Michel A, Peek RM, Jr., Cai Q, Blot WJ. 2013. Helicobacter pylori protein-specific antibodies and risk of colorectal cancer. Cancer Epidemiol Biomarkers Prev. 22(11):1964-1974. http://dx.doi.org/10.1158/1055-9965.EPI-13-0702

Epplein M, Signorello LB, Zheng W, Peek RM, Jr., Michel A, Williams SM, Pawlita M, Correa P, Cai Q, Blot WJ. 2011. Race, African ancestry, and Helicobacter pylori infection in a lowincome United States population. Cancer Epidemiol Biomarkers Prev. 20(5):826-834. http://dx.doi.org/10.1158/1055-9965.EPI-10-1258

Epplein M, Zheng W, Li H, Peek RM, Jr., Correa P, Gao J, Michel A, Pawlita M, Cai Q, Xiang YB et al. 2014. Diet, Helicobacter pylori strain-specific infection, and gastric cancer risk among Chinese men. Nutr Cancer. 66(4):550-557. http://dx.doi.org/10.1080/01635581.2014.894096

Ferlay J, Soerjomataram I, Ervik M, Dikshit R, Eser S, Mathers C, Rebelo M, Parkin DM, Forman D, Bray F. 2013. GLOBOCAN 2012 v1.0, cancer incidence and mortality worldwide: IARC CancerBase No. 11 [Internet]. Lyon, France: International Agency for Research on Cancer (IARC). http://globocan.iarc.fr.

Fernández de Larrea-Baz N, Michel A, Romero B, Pérez-Gómez B, Moreno V, Martín V, Dierssen-Sotos T, Jiménez-Moleón JJ, Castilla J, Tardón A et al. 2017. Helicobacter pylori 
antibody reactivities and colorectal cancer risk in a case-control study in Spain. Front Microbiol. 8:888. http://dx.doi.org/10.3389/fmicb.2017.00888

Ferreccio C. 2014. Chapter 1.4 The regional status of current or planned gastric cancer prevention strategies in Latin America. In: Helicobacter pylori Eradication as a Strategy for Preventing Gastric Cancer. Lyon, France: International Agency for Research on Cancer. p. 3743.

Figura N, Marano L, Moretti E, Ponzetto A. 2016. Helicobacter pylori infection and gastric carcinoma: Not all the strains and patients are alike. World J Gastrointest Oncol. 8(1):40-54. http://dx.doi.org/10.4251/wjgo.v8.i1.40

Fischbach W. 2014. Gastric MALT lymphoma - update on diagnosis and treatment. Best Pract Res Clin Gastroenterol. 28(6):1069-1077. http://dx.doi.org/10.1016/j.bpg.2014.09.006

Fitzmaurice C, Allen C, Barber RM, Barregard L, Bhutta ZA, Brenner H, Dicker DJ, ChimedOrchir O, Dandona R, Dandona L et al. 2017. Global, regional, and national cancer incidence, mortality, years of life lost, years lived with disability, and disability-adjusted life-years for 32 cancer groups, 1990 to 2015: A systematic analysis for the Global Burden of Disease Study. JAMA Oncol. 3(4):524-548. http://dx.doi.org/10.1001/jamaoncol.2016.5688

Ford AC, Forman D, Hunt RH, Yuan Y, Moayyedi P. 2014. Helicobacter pylori eradication therapy to prevent gastric cancer in healthy asymptomatic infected individuals: Systematic review and meta-analysis of randomised controlled trials. BMJ. 348:g3174.

http://dx.doi.org/10.1136/bmj.g3174

Forman D, Sierra M. 2014. Introduction. The current and projected global burden of gastric cancer. In: Helicobacter pylori Eradication as a Strategy for Preventing Gastric Cancer. Lyon, France: International Agency for Research on Cancer. p. 5-15.

Franco AT, Israel DA, Washington MK, Krishna U, Fox JG, Rogers AB, Neish AS, CollierHyams L, Perez-Perez GI, Hatakeyama M et al. 2005. Activation of beta-catenin by carcinogenic Helicobacter pylori. Proc Natl Acad Sci U S A. 102(30):10646-10651.

http://dx.doi.org/10.1073/pnas.0504927102

Franco AT, Johnston E, Krishna U, Yamaoka Y, Israel DA, Nagy TA, Wroblewski LE, Piazuelo MB, Correa P, Peek RM, Jr. 2008. Regulation of gastric carcinogenesis by Helicobacter pylori virulence factors. Cancer Res. 68(2):379-387. http://dx.doi.org/10.1158/0008-5472.CAN-07$\underline{0824}$

Fukase K, Kato M, Kikuchi S, Inoue K, Uemura N, Okamoto S, Terao S, Amagai K, Hayashi S, Asaka M et al. 2008. Effect of eradication of Helicobacter pylori on incidence of metachronous gastric carcinoma after endoscopic resection of early gastric cancer: An open-label, randomised controlled trial. Lancet. 372(9636):392-397. http://dx.doi.org/10.1016/S0140-6736(08)61159-9

Fukui T, Okazaki K, Tamaki H, Kawasaki K, Matsuura M, Asada M, Nishi T, Uchida K, Iwano $\mathrm{M}$, Ohana $\mathrm{M}$ et al. 2004. Immunogenetic analysis of gastric MALT lymphoma-like lesions induced by Helicobacter pylori infection in neonatally thymectomized mice. Lab Invest. 84(4):485-492. http://dx.doi.org/10.1038/labinvest.3700056 
Gawin A, Wex T, Lawniczak M, Malfertheiner P, Starzynska T. 2012. [Helicobacter pylori infection in pancreatic cancer]. Pol Merkur Lekarski. 32(188):103-107.

Gisbert JP, Greenberg ER. 2014. Chapter 3.2. Potential regimens for the mass eradication of Helicobacter pylori infection. In: Helicobacter pylori Eradication as a Strategy for Preventing Gastric Cancer. Lyon, France: International Agency for Research on Cancer. p. 95-110.

González CA, Megraud F, Buissonniere A, Lujan Barroso L, Agudo A, Duell EJ, BoutronRuault MC, Clavel-Chapelon F, Palli D, Krogh V et al. 2012. Helicobacter pylori infection assessed by ELISA and by immunoblot and noncardia gastric cancer risk in a prospective study: The Eurgast-EPIC project. Ann Oncol. 23(5):1320-1324.

http://dx.doi.org/10.1093/annonc/mdr384

Graham DY. 2015. Helicobacter pylori update: gastric cancer, reliable therapy, and possible benefits. Gastroenterology. 148(4):719-731. http://dx.doi.org/10.1053/j.gastro.2015.01.040

Helicobacter Cancer Collaborative Group. 2001. Gastric cancer and Helicobacter pylori: A combined analysis of 12 case control studies nested within prospective cohorts. Gut. 49(3):347353. http://dx.doi.org/10.1136/gut.49.3.347

Hernández DBP, Sabogal IAR, Arenas JDT. 2014. Efficacy of eradicating Helicobacter pylori for prevention of gastric cancer: Systematic review and meta-analysis. Rev Colomb Gastroenterol. 29(3):262-269.

Herrero R, Park JY, Forman D. 2014. The fight against gastric cancer - the IARC Working Group report. Best Pract Res Clin Gastroenterol. 28(6):1107-1114.

http://dx.doi.org/10.1016/j.bpg.2014.10.003

Hooi JKY, Lai WY, Ng WK, Suen MMY, Underwood FE, Tanyingoh D, Malfertheiner P, Graham DY, Wong VWS, Wu JCY et al. 2017. Global prevalence of Helicobacter pylori infection: Systematic review and meta-analysis. Gastroenterology. 153(2):420-429. http://dx.doi.org/10.1053/j.gastro.2017.04.022

Hsu WY, Lin CH, Lin CC, Sung FC, Hsu CP, Kao CH. 2014. The relationship between Helicobacter pylori and cancer risk. Eur J Intern Med. 25(3):235-240.

http://dx.doi.org/10.1016/j.ejim.2014.01.009

Hu Y, Wan JH, Li XY, Zhu Y, Graham DY, Lu NH. 2017. Systematic review with metaanalysis: The global recurrence rate of Helicobacter pylori. Aliment Pharmacol Ther. 46(9):773779. http://dx.doi.org/10.1111/apt.14319

Huang J, Zagai U, Hallmans G, Nyrén O, Engstrand L, Stolzenberg-Solomon R, Duell EJ, Overvad K, Katzke VA, Kaaks R et al. 2017. Helicobacter pylori infection, chronic corpus atrophic gastritis and pancreatic cancer risk in the European Prospective Investigation into Cancer and Nutrition (EPIC) cohort: A nested case-control study. Int J Cancer. 140(8):17271735. http://dx.doi.org/10.1002/ijc.30590

Huang JQ, Zheng GF, Sumanac K, Irvine EJ, Hunt RH. 2003. Meta-analysis of the relationship between cagA seropositivity and gastric cancer. Gastroenterology. 125(6):1636-1644.

http://dx.doi.org/10.1053/j.gastro.2003.08.033 
International Agency for Research on Cancer (IARC). 2012. Helicobacter pylori. In: Biological Agents. Lyon, France: International Agency for Research on Cancer. p. 365-435.

International Agency for Research on Cancer (IARC). 2014. Helicobacter pylori eradication as a strategy for preventing gastric cancer. Lyon, France: International Agency for Research on Cancer. IARC Working Group, vol. 8.

Ishaq S, Nunn L. 2015. Helicobacter pylori and gastric cancer: A state of the art review. Gastroenterol Hepatol Bed Bench. 8(Suppl 1):S6-S14.

Jones NL, Koletzko S, Goodman K, Bontems P, Cadranel S, Casswall T, Czinn S, Gold BD, Guarner J, Elitsur Y et al. 2017. Joint ESPGHAN/NASPGHAN guidelines for the management of Helicobacter pylori in children and adolescents (Update 2016). J Pediatr Gastroenterol Nutr. 64(6):991-1003. http://dx.doi.org/10.1097/MPG.0000000000001594

Kato S, Tachikawa T, Ozawa K, Konno M, Okuda M, Fujisawa T, Nakazato Y, Tajiri H, Iinuma K. 2001. Urine-based enzyme-linked immunosorbent assay for the detection of Helicobacter pylori infection in children. Pediatrics. 107(6):E87. http://dx.doi.org/10.1542/peds.107.6.e87

Khalifa MM, Sharaf RR, Aziz RK. 2010. Helicobacter pylori: A poor man's gut pathogen? Gut Pathog. 2(1):2. http://dx.doi.org/10.1186/1757-4749-2-2

Krueger WS, Hilborn ED, Converse RR, Wade TJ. 2015. Environmental risk factors associated with Helicobacter pylori seroprevalence in the United States: A cross-sectional analysis of NHANES data. Epidemiol Infect. 143(12):2520-2531. http://dx.doi.org/10.1017/S0950268814003938

Lansdorp-Vogelaar I, Sharp L. 2013. Cost-effectiveness of screening and treating Helicobacter pylori for gastric cancer prevention. Best Pract Res Clin Gastroenterol. 27(6):933-947. http://dx.doi.org/10.1016/j.bpg.2013.09.005

Lee CW, Rickman B, Rogers AB, Ge Z, Wang TC, Fox JG. 2008. Helicobacter pylori eradication prevents progression of gastric cancer in hypergastrinemic INS-GAS mice. Cancer Res. 68(9):3540-3548. http://dx.doi.org/10.1158/0008-5472.CAN-07-6786

Lee SY. 2014a. Current progress toward eradicating Helicobacter pylori in East Asian countries: Differences in the 2013 revised guidelines between China, Japan, and South Korea. World J Gastroenterol. 20(6):1493-1502. http://dx.doi.org/10.3748/wjg.v20.i6.1493

Lee YC. 2014b. Chapter 1.3 The regional status of current or planned gastric cancer prevention strategies in Taiwan, China. In: Helicobacter pylori Eradication as a Strategy for Preventing Gastric Cancer. Lyon, France: International Agency for Research on Cancer. p. 28-36.

Lee YC, Chen TH, Chiu HM, Shun CT, Chiang H, Liu TY, Wu MS, Lin JT. 2013. The benefit of mass eradication of Helicobacter pylori infection: A community-based study of gastric cancer prevention. Gut. 62(5):676-682. http://dx.doi.org/10.1136/gutjnl-2012-302240

Lee YC, Chiang TH, Chou CK, Tu YK, Liao WC, Wu MS, Graham DY. 2016. Association between Helicobacter pylori eradication and gastric cancer incidence: A systematic review and meta-analysis. Gastroenterology. 150(5):1113-1124.

http://dx.doi.org/10.1053/j.gastro.2016.01.028 
Lee YC, Lin JT. 2017. Screening and treating Helicobacter pylori infection for gastric cancer prevention on the population level. J Gastroenterol Hepatol. 32(6):1160-1169.

http://dx.doi.org/10.1111/jgh.13726

Lee YC, Lin JT, Wu HM, Liu TY, Yen MF, Chiu HM, Wang HP, Wu MS, Hsiu-Hsi Chen T. 2007. Cost-effectiveness analysis between primary and secondary preventive strategies for gastric cancer. Cancer Epidemiol Biomarkers Prev. 16(5):875-885.

http://dx.doi.org/10.1158/1055-9965.EPI-06-0758

Leja M, Axon A, Brenner H. 2016. Epidemiology of Helicobacter pylori infection. Helicobacter. 21 Suppl 1:3-7. http://dx.doi.org/10.1111/hel.12332

Leja M, Park JY, Murillo R, Liepniece-Karele I, Isajevs S, Kikuste I, Rudzite D, Krike P, Parshutin S, Polaka I et al. 2017. Multicentric randomised study of Helicobacter pylori eradication and pepsinogen testing for prevention of gastric cancer mortality: The GISTAR study. BMJ Open. 7(8):e016999. http://dx.doi.org/10.1136/bmjopen-2017-016999

Leja M, Park YY, Plummer M, Herrero R. 2014. Chapter 4.2. Multicentre randomized study of Helicobacter pylori eradication and pepsinogen testing for prevention of gastric cancer mortality (gastric cancer prevention study by predicting atrophic gastritis; GISTAR). In: Helicobacter pylori Eradication as a Strategy for Preventing Gastric Cancer. Lyon, France: International Agency for Research on Cancer. p. 147-153.

Leung WK, Lin SR, Ching JY, To KF, Ng EK, Chan FK, Lau JY, Sung JJ. 2004. Factors predicting progression of gastric intestinal metaplasia: Results of a randomised trial on Helicobacter pylori eradication. Gut. 53(9):1244-1249.

http://dx.doi.org/10.1136/gut.2003.034629

Li Q, Liu J, Gong Y, Yuan Y. 2017. Association of CagA EPIYA-D or EPIYA-C phosphorylation sites with peptic ulcer and gastric cancer risks: A meta-analysis. Medicine (Baltimore). 96(17):e6620. http://dx.doi.org/10.1097/MD.0000000000006620

Li WQ, Ma JL, Zhang L, Brown LM, Li JY, Shen L, Pan KF, Liu WD, Hu Y, Han ZX et al. 2014. Effects of Helicobacter pylori treatment on gastric cancer incidence and mortality in subgroups. J Natl Cancer Inst. 106(7). http://dx.doi.org/10.1093/jnci/dju116

Limburg PJ, Stolzenberg-Solomon RZ, Colbert LH, Perez-Perez GI, Blaser MJ, Taylor PR, Virtamo J, Albanes D. 2002. Helicobacter pylori seropositivity and colorectal cancer risk: A prospective study of male smokers. Cancer Epidemiol Biomarkers Prev. 11(10 Pt 1):1095-1099.

Liu H, Merrell DS, Semino-Mora C, Goldman M, Rahman A, Mog S, Dubois A. 2009. Diet synergistically affects Helicobacter pylori-induced gastric carcinogenesis in nonhuman primates. Gastroenterology. 137(4):1367-1379.e1361-1366. http://dx.doi.org/10.1053/j.gastro.2009.07.041

Logan RP, Walker MM. 2001. ABC of the upper gastrointestinal tract: Epidemiology and diagnosis of Helicobacter pylori infection. BMJ. 323(7318):920-922.

http://dx.doi.org/10.1136/bmj.323.7318.920

Long Parma D, Muñoz E, Ogden SM, Westin GF, Leach RJ, Thompson IM, Ramirez AG. 2017. Helicobacter pylori infection in Texas Hispanic and non-Hispanic white men: Implications for 
gastric cancer risk disparities. Am J Mens Health. 11(4):1039-1045. http://dx.doi.org/10.1177/1557988317702038

Ma JL, Zhang L, Brown LM, Li JY, Shen L, Pan KF, Liu WD, Hu Y, Han ZX, Crystal-Mansour $\mathrm{S}$ et al. 2012. Fifteen-year effects of Helicobacter pylori, garlic, and vitamin treatments on gastric cancer incidence and mortality. J Natl Cancer Inst. 104(6):488-492.

http://dx.doi.org/10.1093/jnci/djs003

Machida-Montani A, Sasazuki S, Inoue M, Natsukawa S, Shaura K, Koizumi Y, Kasuga Y, Hanaoka T, Tsugane S. 2007. Atrophic gastritis, Helicobacter pylori, and colorectal cancer risk: A case-control study. Helicobacter. 12(4):328-332. http://dx.doi.org/10.1111/j.15235378.2007.00513.X

Maeda M, Moro H, Ushijima T. 2017. Mechanisms for the induction of gastric cancer by Helicobacter pylori infection: Aberrant DNA methylation pathway. Gastric Cancer. 20(Suppl 1):8-15. http://dx.doi.org/10.1007/s10120-016-0650-0

Mahachai V, Vilaichone RK, Pittayanon R, Rojborwonwitaya J, Leelakusolvong S, Maneerattanaporn M, Chotivitayatarakorn P, Treeprasertsuk S, Kositchaiwat C, Pisespongsa P et al. 2018. Helicobacter pylori management in ASEAN: The Bangkok consensus report. J Gastroenterol Hepatol. 33(1):37-56. http://dx.doi.org/10.1111/jgh.13911

Malfertheiner P, Megraud F, O'Morain CA, Gisbert JP, Kuipers EJ, Axon AT, Bazzoli F, Gasbarrini A, Atherton J, Graham DY et al. 2017. Management of Helicobacter pylori infectionthe Maastricht V/Florence consensus report. Gut. 66(1):6-30. http://dx.doi.org/10.1136/gutjnl$\underline{2016-312288}$

Malnick SD, Melzer E, Attali M, Duek G, Yahav J. 2014. Helicobacter pylori: Friend or foe? World J Gastroenterol. 20(27):8979-8985.

Mateos-Muñoz B, Pérez-de-la-Serna J, Ruiz-de-León A, Serrano-Falcón B, Casabona-Francés S, Velasco-Cerrudo A, Rey-Diaz-Rubio E. 2013. Enterohepatic Helicobacter other than Helicobacter pylori. Rev Esp Enferm Dig. 105(8):477-484. http://dx.doi.org/10.4321/S1130$\underline{01082013000800006}$

Mera R, Fontham ET, Bravo LE, Bravo JC, Piazuelo MB, Camargo MC, Correa P. 2005. Long term follow up of patients treated for Helicobacter pylori infection. Gut. 54(11):1536-1540. http://dx.doi.org/10.1136/gut.2005.072009

Mera RM, Bravo LE, Camargo MC, Bravo JC, Delgado AG, Romero-Gallo J, Yepez MC, Realpe JL, Schneider BG, Morgan DR et al. 2017. Dynamics of Helicobacter pylori infection as a determinant of progression of gastric precancerous lesions: 16-year follow-up of an eradication trial. Gut. 67(7):1239-1246. http://dx.doi.org/10.1136/gutjnl-2016-311685

Mitchell H, English DR, Elliott F, Gengos M, Barrett JH, Giles GG, Forman D. 2008. Immunoblotting using multiple antigens is essential to demonstrate the true risk of Helicobacter pylori infection for gastric cancer. Aliment Pharmacol Ther. 28(7):903-910. 
Moayyedi P. 2014. Chapter 3.3. Feasibility and cost-effectiveness of population-based Helicobacter pylori eradication. In: Helicobacter pylori Eradication as a Strategy for Preventing Gastric Cancer. Lyon, France: International Agency for Research on Cancer. p. 111-121.

Morgan DR, Torres J, Sexton R, Herrero R, Salazar-Martínez E, Greenberg ER, Bravo LE, Dominguez RL, Ferreccio C, Lazcano-Ponce EC et al. 2013. Risk of recurrent Helicobacter pylori infection 1 year after initial eradication therapy in 7 Latin American communities. JAMA. 309(6):578-586. http://dx.doi.org/10.1001/jama.2013.311

National Toxicology Program (NTP). 2016. Draft report on carcinogens concept. Helicobacter pylori: Chronic infection. Research Triangle Park, NC: National Toxicology Program.

Nobel Prize. 2005. Press release: Nobel Prize in Physiology or Medicine for 2005 awarded to Barry J. Marshall and J. Robin Warren. Nobel Media AB. https://www.nobelprize.org/nobel_prizes/medicine/laureates/2005/press.html. [Last updated: October 3, 2005]

Nozaki K, Shimizu N, Inada K, Tsukamoto T, Inoue M, Kumagai T, Sugiyama A, Mizoshita T, Kaminishi M, Tatematsu M. 2002. Synergistic promoting effects of Helicobacter pylori infection and high-salt diet on gastric carcinogenesis in Mongolian gerbils. Jpn J Cancer Res. 93(10):1083-1089. http://dx.doi.org/10.1111/j.1349-7006.2002.tb01209.x

Ohata H, Kitauchi S, Yoshimura N, Mugitani K, Iwane M, Nakamura H, Yoshikawa A, Yanaoka K, Arii K, Tamai H et al. 2004. Progression of chronic atrophic gastritis associated with Helicobacter pylori infection increases risk of gastric cancer. Int J Cancer. 109(1):138-143. http://dx.doi.org/10.1002/ijc.11680

Pan KF, Zhang L, Gerhard M, Ma JL, Liu WD, Ulm K, Wang JX, Zhang L, Zhang Y, Bajbouj M et al. 2016. A large randomised controlled intervention trial to prevent gastric cancer by eradication of Helicobacter pylori in Linqu County, China: Baseline results and factors affecting the eradication. Gut. 65(1):9-18. http://dx.doi.org/10.1136/gutjnl-2015-309197

Park JB, Koo JS. 2014. Helicobacter pylori infection in gastric mucosa-associated lymphoid tissue lymphoma. World J Gastroenterol. 20(11):2751-2759.

http://dx.doi.org/10.3748/wjg.v20.i11.2751

Park JY, Forman D, Greenberg ER, Herrero R. 2013. Helicobacter pylori eradication in the prevention of gastric cancer: Are more trials needed? Curr Oncol Rep. 15(6):517-525. http://dx.doi.org/10.1007/s11912-013-0341-5

Park JY, Nam BH, Herrero R, Choi IJ. 2017. Effect of Helicobacter pylori eradication on gastric cancer prevention in Korea: A randomized controlled clinical trial. In: Matsui S, Crowley J, editors. Frontiers of Biostatistical Methods and Applications in Clinical Oncology. Singapore: Springer. p. 315-330.

Parsonnet J. 2014. Chapter 2.2. Are there benefits of Helicobacter pylori infection? In: Helicobacter pylori Eradication as a Strategy for Preventing Gastric Cancer. Lyon, France: International Agency for Research on Cancer. p. 72-79. 
Parsonnet J, Hansen S, Rodriguez L, Gelb AB, Warnke RA, Jellum E, Orentreich N, Vogelman JH, Friedman GD. 1994. Helicobacter pylori infection and gastric lymphoma. N Engl J Med. 330(18):1267-1271. http://dx.doi.org/10.1056/NEJM199405053301803

Pereira MI, Medeiros JA. 2014. Role of Helicobacter pylori in gastric mucosa-associated lymphoid tissue lymphomas. World J Gastroenterol. 20(3):684-698.

http://dx.doi.org/10.3748/wjg.v20.i3.684

Plummer M, Franceschi S, Vignat J, Forman D, de Martel C. 2015. Global burden of gastric cancer attributable to Helicobacter pylori. Int J Cancer. 136(2):487-490.

http://dx.doi.org/10.1002/ijc.28999

Raderer M, Wrba F, Kornek G, Maca T, Koller DY, Weinlaender G, Hejna M, Scheithauer W. 1998. Association between Helicobacter pylori infection and pancreatic cancer. Oncology. 55(1):16-19. http://dx.doi.org/10.1159/000011830

Reynders MB, Miendje Deyi VY, Dahma H, Scheper T, Hanke M, Decolvenaer M, Dediste A. 2012. Performance of individual Helicobacter pylori antigens in the immunoblot-based detection of H. pylori infection. FEMS Immunol Med Microbiol. 64(3):352-363.

http://dx.doi.org/10.1111/j.1574-695X.2011.00920.x

Risch HA, Lu L, Kidd MS, Wang J, Zhang W, Ni Q, Gao YT, Yu H. 2014. Helicobacter pylori seropositivities and risk of pancreatic carcinoma. Cancer Epidemiol Biomarkers Prev. 23(1):172178. http://dx.doi.org/10.1158/1055-9965.EPI-13-0447

Risch HA, Yu H, Lu L, Kidd MS. 2010. ABO blood group, Helicobacter pylori seropositivity, and risk of pancreatic cancer: A case-control study. J Natl Cancer Inst. 102(7):502-505. http://dx.doi.org/10.1093/jnci/djq007

Rokkas T, Sechopoulos P, Pistiolas D, Kothonas F, Margantinis G, Koukoulis G. 2013. The relationship of Helicobacter pylori infection and colon neoplasia, on the basis of meta-analysis. Eur J Gastroenterol Hepatol. 25(11):1286-1294.

http://dx.doi.org/10.1097/MEG.0b013e328363d3cd

Romero-Gallo J, Harris EJ, Krishna U, Washington MK, Perez-Perez GI, Peek RM, Jr. 2008. Effect of Helicobacter pylori eradication on gastric carcinogenesis. Lab Invest. 88(3):328-336. http://dx.doi.org/10.1038/labinvest.3700719

Sachs G, Scott DR, Wen Y. 2011. Gastric infection by Helicobacter pylori. Curr Gastroenterol Rep. 13(6):540-546. http://dx.doi.org/10.1007/s11894-011-0226-4

Saito D, Boku N, Fujioka T, Fukuda Y, Matsushima Y, Sakaki N, Sato K, Sugiyama T, Takahashi S, Sato T et al. 2005. Impact of H. pylori eradication on gastric cancer prevention: Endoscopic results of the Japanese intervention trial (JITHP-Study): A randomized multi-center trial. Gastroenterology. 128(Suppl 2):A4.

Schulte A, Pandeya N, Fawcett J, Fritschi L, Risch HA, Webb PM, Whiteman DC, Neale RE. 2015. Association between Helicobacter pylori and pancreatic cancer risk: A meta-analysis. Cancer Causes Control. 26(7):1027-1035. http://dx.doi.org/10.1007/s10552-015-0595-3 
Schulz TR, McBryde ES, Leder K, Biggs BA. 2014. Using stool antigen to screen for Helicobacter pylori in immigrants and refugees from high prevalence countries is relatively cost effective in reducing the burden of gastric cancer and peptic ulceration. PLoS One. 9(9):e108610. http://dx.doi.org/10.1371/journal.pone.0108610

Servetas SL, Bridge DR, Merrell DS. 2016. Molecular mechanisms of gastric cancer initiation and progression by Helicobacter pylori. Curr Opin Infect Dis. 29(3):304-310. http://dx.doi.org/10.1097/QCO.0000000000000248

Sheu BS, Wu MS, Chiu CT, Lo JC, Wu DC, Liou JM, Wu CY, Cheng HC, Lee YC, Hsu PI et al. 2017. Consensus on the clinical management, screening-to-treat, and surveillance of Helicobacter pylori infection to improve gastric cancer control on a nationwide scale. Helicobacter. 22(3). http://dx.doi.org/10.1111/hel.12368

Shimoyama T, Takahashi R, Abe D, Mizuki I, Endo T, Fukuda S. 2010. Serological analysis of Helicobacter hepaticus infection in patients with biliary and pancreatic diseases. J Gastroenterol Hepatol. 25(Suppl 1):S86-89. http://dx.doi.org/10.1111/j.1440-1746.2010.06224.x

Siao D, Somsouk M. 2014. Helicobacter pylori: Evidence-based review with a focus on immigrant populations. J Gen Intern Med. 29(3):520-528. http://dx.doi.org/10.1007/s11606-013$\underline{2630-y}$

Simán JH, Engstrand L, Berglund G, Forsgren A, Florén CH. 2007. Helicobacter pylori and CagA seropositivity and its association with gastric and oesophageal carcinoma. Scand J Gastroenterol. 42(8):933-940. http://dx.doi.org/10.1080/00365520601173863

Song ZQ, Zhou LY. 2015. Helicobacter pylori and gastric cancer: Clinical aspects. Chin Med J. 128(22):3101-3105. http://dx.doi.org/10.4103/0366-6999.169107

Stolzenberg-Solomon RZ, Blaser MJ, Limburg PJ, Perez-Perez G, Taylor PR, Virtamo J, Albanes D. 2001. Helicobacter pylori seropositivity as a risk factor for pancreatic cancer. J Natl Cancer Inst. 93(12):937-941. http://dx.doi.org/10.1093/jnci/93.12.937

Sugano K, Tack J, Kuipers EJ, Graham DY, El-Omar EM, Miura S, Haruma K, Asaka M, Uemura N, Malfertheiner P et al. 2015. Kyoto global consensus report on Helicobacter pylori gastritis. Gut. 64(9):1353-1367. http://dx.doi.org/10.1136/gutjnl-2015-309252

Suh M, Choi KS, Lee YY, Jun JK. 2013. Trends in cancer screening rates among Korean men and women: Results from the Korean National Cancer Screening Survey, 2004-2012. Cancer Res Treat. 45(2):86-94. http://dx.doi.org/10.4143/crt.2013.45.2.86

Surveillance Epidemiology and End Results Program (SEER). 2018. Cancer stat facts: Stomach cancer. Washington, DC: National Cancer Institute.

https://seer.cancer.gov/statfacts/html/stomach.html.

Sutton P, Boag JM. 2018. Status of vaccine research and development for Helicobacter pylori. Vaccine. (ePub ahead of print).

Taylor VM, Ko LK, Hwang JH, Sin MK, Inadomi JM. 2014. Gastric cancer in Asian American populations: A neglected health disparity. Asian Pac J Cancer Prev. 15(24):10565-10571.

http://dx.doi.org/10.7314/APJCP.2014.15.24.10565 
Teng AM, Kvizhinadze G, Nair N, McLeod M, Wilson N, Blakely T. 2017. A screening program to test and treat for Helicobacter pylori infection: Cost-utility analysis by age, sex and ethnicity. BMC Infect Dis. 17(1):156. http://dx.doi.org/10.1186/s12879-017-2259-2

Testerman TL, Morris J. 2014. Beyond the stomach: An updated view of Helicobacter pylori pathogenesis, diagnosis, and treatment. World J Gastroenterol. 20(36):12781-12808. http://dx.doi.org/10.3748/wjg.v20.i36.12781

Thung I, Aramin H, Vavinskaya V, Gupta S, Park JY, Crowe SE, Valasek MA. 2016. Review article: The global emergence of Helicobacter pylori antibiotic resistance. Aliment Pharmacol Ther. 43(4):514-533. http://dx.doi.org/10.1111/apt.13497

Torres J, Correa P, Herrero R, Piazuelo MB, Ferreccio C. 2016. Population-based strategies for Helicobacter pylori-associated disease management: Latin American perspective. In: Backert S, Yamaoka Y, editors. Helicobacter pylori Research: From Bench to Bedside. Springer Japan. p. 503-518.

U.S. Environmental Protection Agency (USEPA). 2016. Contaminant Information Sheets (CISs) for the final fourth Contaminant Candidate List (CCL 4). Washington, DC: U.S. Environmental Protection Agency. EPA 815-R-16-003.

U.S. Food and Drug Administration (FDA). 2017. Vaccines licensed for use in the United States. U.S. Food and Drug Administration.

https://www.fda.gov/BiologicsBloodVaccines/Vaccines/ApprovedProducts/ucm093833.htm. [Last accessed: December 7, 2017]

Wald NJ. 2014. Chapter 4.5. The treatment of Helicobacter pylori infection of the stomach in relation to the possible prevention of gastric cancer. In: Helicobacter pylori Eradication as a Strategy for Preventing Gastric Cancer. Lyon, France: International Agency for Research on Cancer. p. 174-181.

Wang F, Sun MY, Shi SL, Lv ZS. 2014. Helicobacter pylori infection and normal colorectal mucosa-adenomatous polyp-adenocarcinoma sequence: A meta-analysis of 27 case-control studies. Colorectal Dis. 16(4):246-252. http://dx.doi.org/10.1111/codi.12290

Wang MY, Liu XF, Gao XZ. 2015. Helicobacter pylori virulence factors in development of gastric carcinoma. Future Microbiol. 10(9):1505-1516. http://dx.doi.org/10.2217/fmb.15.72

Wang X, Willén R, Svensson M, Ljungh A, Wadström T. 2003. Two-year follow-up of Helicobacter pylori infection in C57BL/6 and Balb/cA mice. APMIS. 111(4):514-522. http://dx.doi.org/10.1034/j.1600-0463.2003.1110410.x

Wong BC, Lam SK, Wong WM, Chen JS, Zheng TT, Feng RE, Lai KC, Hu WH, Yuen ST, Leung SY et al. 2004. Helicobacter pylori eradication to prevent gastric cancer in a high-risk region of China: A randomized controlled trial. JAMA. 291(2):187-194.

http://dx.doi.org/10.1001/jama.291.2.187

Wong BC, Zhang L, Ma JL, Pan KF, Li JY, Shen L, Liu WD, Feng GS, Zhang XD, Li J et al. 2012. Effects of selective COX-2 inhibitor and Helicobacter pylori eradication on precancerous gastric lesions. Gut. 61(6):812-818. http://dx.doi.org/10.1136/gutjnl-2011-300154 
Wong IO, Schooling CM, Cowling BJ. 2014. Cost-effectiveness of Helicobacter pylori screening and treatment for gastric cancer in Hong Kong: A decision analytic approach. Hong Kong Med J. 20(Suppl 7):13-15.

Wu Q, Yang ZP, Xu P, Gao LC, Fan DM. 2013. Association between Helicobacter pylori infection and the risk of colorectal neoplasia: A systematic review and meta-analysis. Colorectal Dis. 15(7):e352-e364. http://dx.doi.org/10.1111/codi.12284

Wündisch T, Dieckhoff P, Greene B, Thiede C, Wilhelm C, Stolte M, Neubauer A. 2012. Second cancers and residual disease in patients treated for gastric mucosa-associated lymphoid tissue lymphoma by Helicobacter pylori eradication and followed for 10 years. Gastroenterology. 143(4):936-942; quiz e913-e914. http://dx.doi.org/10.1053/j.gastro.2012.06.035

Xie F, O'Reilly D, Ferrusi IL, Blackhouse G, Bowen JM, Tarride JE, Goeree R. 2009. Illustrating economic evaluation of diagnostic technologies: Comparing Helicobacter pylori screening strategies in prevention of gastric cancer in Canada. J Am Coll Radiol. 6(5):317-323. http://dx.doi.org/10.1016/j.jacr.2009.01.022

Yamaoka Y, Graham DY. 2014. Helicobacter pylori virulence and cancer pathogenesis. Future Oncol. 10(8):1487-1500. http://dx.doi.org/10.2217/fon.14.29

Yeh JM, Hur C, Ward Z, Schrag D, Goldie SJ. 2016. Gastric adenocarcinoma screening and prevention in the era of new biomarker and endoscopic technologies: A cost-effectiveness analysis. Gut. 65(4):563-574. http://dx.doi.org/10.1136/gutjnl-2014-308588

Yeh JM, Kuntz KM, Ezzati M, Goldie SJ. 2009. Exploring the cost-effectiveness of Helicobacter pylori screening to prevent gastric cancer in China in anticipation of clinical trial results. Int $\mathbf{J}$ Cancer. 124(1):157-166. http://dx.doi.org/10.1002/ijc.23864

Yoon SB, Park JM, Lim CH, Cho YK, Choi MG. 2014. Effect of Helicobacter pylori eradication on metachronous gastric cancer after endoscopic resection of gastric tumors: A meta-analysis. Helicobacter. 19(4):243-248. http://dx.doi.org/10.1111/hel.12146

Yoshida T, Kato J, Inoue I, Yoshimura N, Deguchi H, Mukoubayashi C, Oka M, Watanabe M, Enomoto S, Niwa T et al. 2014. Cancer development based on chronic active gastritis and resulting gastric atrophy as assessed by serum levels of pepsinogen and Helicobacter pylori antibody titer. Int J Cancer. 134(6):1445-1457. http://dx.doi.org/10.1002/ijc.28470

You WC, Brown LM, Zhang L, Li JY, Jin ML, Chang YS, Ma JL, Pan KF, Liu WD, Hu Y et al. 2006. Randomized double-blind factorial trial of three treatments to reduce the prevalence of precancerous gastric lesions. J Natl Cancer Inst. 98(14):974-983.

http://dx.doi.org/10.1093/jnci/djj264

Yu G, Murphy G, Michel A, Weinstein SJ, Männistö S, Albanes D, Pawlita M, StolzenbergSolomon RZ. 2013. Seropositivity to Helicobacter pylori and risk of pancreatic cancer. Cancer Epidemiol Biomarkers Prev. 22(12):2416-2419. http://dx.doi.org/10.1158/1055-9965.EPI-13$\underline{0680}$

Zagari RM, Romano M, Ojetti V, Stockbrugger R, Gullini S, Annibale B, Farinati F, Ierardi E, Maconi G, Rugge M et al. 2015. Guidelines for the management of Helicobacter pylori infection 
in Italy: The III working group consensus report 2015. Dig Liver Dis. 47(11):903-912. http://dx.doi.org/10.1016/j.dld.2015.06.010

Zeng M, Mao XH, Li JX, Tong WD, Wang B, Zhang YJ, Guo G, Zhao ZJ, Li L, Wu DL et al. 2015. Efficacy, safety, and immunogenicity of an oral recombinant Helicobacter pylori vaccine in children in China: A randomised, double-blind, placebo-controlled, phase 3 trial. Lancet. 386(10002):1457-1464. http://dx.doi.org/10.1016/S0140-6736(15)60310-5

Zhang Y, Hoffmeister M, Weck MN, Chang-Claude J, Brenner H. 2012. Helicobacter pylori infection and colorectal cancer risk: Evidence from a large population-based case-control study in Germany. Am J Epidemiol. 175(5):441-450. http://dx.doi.org/10.1093/aje/kwr331

Zhou L, Lin S, Ding S, Huang X, Jin Z, Cui R, Meng L, Li Y, Zhang L, Guo C et al. 2014. Relationship of Helicobacter pylori eradication with gastric cancer and gastric mucosal histological changes: A 10-year follow-up study. Chin Med J (Engl). 127(8):1454-1458.

Zou QH, Li RQ. 2011. Helicobacter pylori in the oral cavity and gastric mucosa: A metaanalysis. J Oral Pathol Med. 40(4):317-324. http://dx.doi.org/10.1111/j.1600-0714.2011.01006.x

Zullo A, Hassan C, Andriani A, Cristofari F, De Francesco V, Ierardi E, Tomao S, Morini S, Vaira D. 2009. Eradication therapy for Helicobacter pylori in patients with gastric MALT lymphoma: A pooled data analysis. Am J Gastroenterol. 104(8):1932-1937; quiz 1938. http://dx.doi.org/10.1038/ajg.2009.314

Zullo A, Hassan C, Cristofari F, Andriani A, De Francesco V, Ierardi E, Tomao S, Stolte M, Morini S, Vaira D. 2010a. Effects of Helicobacter pylori eradication on early stage gastric mucosa-associated lymphoid tissue lymphoma. Clin Gastroenterol Hepatol. 8(2):105-110. http://dx.doi.org/10.1016/j.cgh.2009.07.017

Zullo A, Hassan C, Cristofari F, Perri F, Morini S. 2010b. Gastric low-grade mucosal-associated lymphoid tissue-lymphoma: Helicobacter pylori and beyond. World J Gastrointest Oncol. 2(4):181-186. http://dx.doi.org/10.4251/wjgo.v2.i4.181

Zumkeller N, Brenner H, Chang-Claude J, Hoffmeister M, Nieters A, Rothenbacher D. 2007. Helicobacter pylori infection, interleukin-1 gene polymorphisms and the risk of colorectal cancer: Evidence from a case-control study in Germany. Eur J Cancer. 43(8):1283-1289. http://dx.doi.org/10.1016/j.ejca.2007.03.005 


\section{Abbreviations}

ASEAN Association of Southeast Asian Nations

BabA blood group antigen binding adhesin A

CAG chronic atrophic gastritis

CagA cytotoxin-associated gene A

CI confidence interval

COX 2 cyclooxygenase 2

CPS II Cancer Prevention Study II

DNA deoxyribonucleic acid

DYS dysplasia

ELISA enzyme-linked immunosorbent assay

FDA U.S. Food and Drug Administration

FDASIA Food and Drug Administration Safety and Innovation Act

GAIN Generating Antibiotic Incentives Now

GERD gastro-esophageal reflux disease

HAWC Health Assessment Workspace Collaborative

HDI human development index

HR hazard ratio

IgA immunoglobulin A

IgG immunoglobulin G

IM intestinal metaplasia

IQR interquartile range

MALT mucosa-associated lymphoid tissue

MNU $\quad N$-methyl- $N$-nitrosourea

NHANES National Health and Nutrition Examination Survey (United States)

OR odds ratio

ORoC Office of the Report on Carcinogens

PPI proton pump inhibitor

RoC Report on Carcinogens

RR relative risk

TGF-B transforming growth factor beta

VacA vacuolating cytotoxin A 


\section{Glossary}

Animal reservoir: An animal in which an infectious agent (e.g., H. pylori) lives and multiplies in such a manner that it can be transmitted to a susceptible host.

Antrum: The lower part of the stomach, sometimes called the pyloric antrum.

ASEAN countries: Association of Southeast Asian Nations. The 10 members are Brunei Darussalam, Cambodia, Indonesia, Laos, Malaysia, Myanmar, Philippines, Singapore, Thailand, and Vietnam.

Atrophic gastritis: The end stage of chronic gastritis, in which gastric glandular cells are lost and replace by intestinal and fibrous tissues.

Barrett's esophagus: A complication of gastroesophageal reflux disease (GERD) in which the normal tissue lining the esophagus is altered to resemble the tissue that lines the intestine.

Birth cohort effect: Variations in a characteristic, such as $H$. pylori infection, among individuals that share a common year or range of years of birth.

Bismuth quadruple therapy: A combination of a bismuth salt, a proton pump inhibitor (PPI), and two antibiotics used to treat $H$. pylori infections.

Cardia: The opening that connects the esophagus and the upper part of the stomach or that part of the stomach connected to the esophagus.

Cardia gastric cancer: Cancer of the lining of the stomach found in the top part of the organ (i.e., the cardia).

Chemotaxis: Movement of an organism, for example an $H$. pylori bacterium, in response to a chemical stimulus, including acidity.

Clarithromycin triple therapy: A combination of clarithromycin (an antibiotic), amoxicillin (an antibiotic), and omeprazole (a proton pump inhibitor) used to treat $H$. pylori infections.

Corpus: The body of the stomach, which is the largest of the four parts that make up the stomach.

COX-2 inhibitor: A nonsteroidal anti-inflammatory drug (NSAID) that directly targets cyclooxygenase-2 (COX-2) enzyme.

Enzyme-linked immunosorbent assay (ELISA): An immunological assay commonly used to measure antibodies in biological samples.

Enterohepatic tissues: The intestinal tract, biliary tree, and liver.

EPIYA motif: A polymorphic pattern of Glu-Pro-Ile-Tyr-Ala amino acid repeats that contains the main sites for phosphorylation of CagA.

Flagella (singular flagellum): A whip-like structure that allows a cell to move.

Gastritis: Inflammation, irritation, or erosion of the lining of the stomach. 
Gram-negative bacteria: Bacteria that are not stained by the crystal violet dye used in the Gram stain protocol and thus appear red or pink due to the counterstain (usually safranin).

Helical: A geometric shape that curves continuously around a center point; for example, a line wrapped around a cylinder or a cone.

Immunoblot: A laboratory test that looks for antibodies the body makes against different molecules, or "antigens," that are part of a bacteria, e.g., H. pylori.

INS-GAS transgenic mice: Mice that have been genetically modified to produce more gastrin (a peptide that increases the secretion of gastric acid.

Intervention studies: A test of preventive or therapeutic measure(s) in which study subjects are followed prospectively with one group of subjects receiving the treatment and the other serving as the control; the control group can receive no treatment, a placebo, or a standard treatment for comparison.

Life-years saved: A measure of the additional number of years that a person lives as a result of receiving a treatment.

Mucosal: Related to the mucosa, which is the thin skin that covers the inside surface of body parts such as the nose and mouth and produces mucus to protect them.

Non-cardia gastric cancer: Cancer of the lining of the stomach found in any part of the organ other than the top part (i.e., the cardia).

Peptic ulcers: Open sores that develop on the inside lining of the stomach and the upper portion of the small intestine.

Prevalence: The number of cases of a disease that are present in a particular population at a given time.

Sensitivity: The ability of a clinical test to correctly identify those patients with the disease.

Serology tests: Blood tests that look for antibodies, e.g., to H. pylori.

Specificity: The ability of a clinical test to correctly identify those patients without the disease.

Spiral: A shape consisting of curves, with each one above or wider than the one before.

Tissue biopsy: A sample of tissue removed from the body for closer examination, usually for diagnostic purposes.

Urease: An enzyme that converts urea to ammonia and carbon dioxide. 


\section{Appendix A. Literature Search Strategy \\ Table of Contents}

A.1. Identification of Intervention Studies ...................................................................... A-2

A.2. Identification of Cancer and Exposure Studies, Reviews, and Meta-analyses ................. A-3

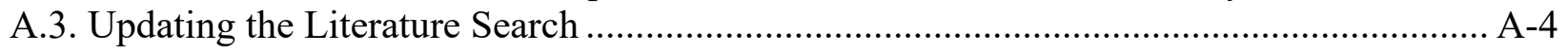

\section{Tables}

Table A-1. Major Topics Searched .................................................................................... A-2

Table A-2. The Full Search Strings for H. pylori Searches ................................................. A-3 
The objective of the literature-search approach was to identify published literature relevant for evaluating the potential carcinogenicity of the Helicobacter pylori (H. pylori) bacterium. As discussed in the Helicobacter pylori Concept Document (NTP 2016), this monograph relies on the IARC (2012) monograph and key studies published since the monograph. Two literature searches were conducted: (1) to identify key reviews or meta-analyses for updating exposure and mechanistic data and for determining whether a formal review of other cancer sites was merited and (2) to identify intervention and prevention studies published since the 2014 publication of the IARC working group report on $H$. pylori eradication.

\section{A.1. Identification of Intervention Studies}

\section{A.1.1. General Approach}

Database searching encompasses selecting databases and search terms, as well as conducting the searches. Searches of several citation databases generally use search terms for the individual topic of interest, along with search terms for cancer and/or specific topics, including epidemiological and mechanistic studies. A critical step in the process involves consultation with an information specialist to develop relevant search terms, which are used to search bibliographic databases. The IARC working group report on H. pylori eradication was published in 2014, so PubMed, Web of Science, and Scopus were searched for new information about H. pylori from 2013 through 2017. Table A-1 highlights the general concepts searched, with selected example terms.

Table A-1. Major Topics Searched

\begin{tabular}{|c|c|}
\hline Topics & Example Terms \\
\hline H. pylori & H-pylori, Helicobacter pylori, Helicobacter-pylori \\
\hline Intervention/prevention & $\begin{array}{l}\text { Controlled before-after studies, Interrupted time series analysis, Early medical } \\
\text { intervention, Treatment, Intervention, Therapy, Prevention }\end{array}$ \\
\hline Study type and topics & $\begin{array}{l}\text { Meta-analysis, Clinical trial, Public health surveillance, Medical economics, Markov } \\
\text { chains, Statistical models, Health care costs, Cost-benefit analysis, Review, Treatment } \\
\text { outcome }\end{array}$ \\
\hline Cancer & Neoplasms, Carcinogenicity tests, Carcinogens \\
\hline
\end{tabular}

The large and complex body of literature for H. pylori was searched through the use of narrowing terms for the relevant major topics within the bibliographic databases. The results were then processed in EndNote to remove duplicates, before being transferred to Health Assessment Workspace Collaborative (HAWC), a computational content management system, for screening.

The bibliographic database search results (1,198 references) were processed in EndNote and then imported into HAWC for first- and second-tier screening. Relevant studies found through the citations in review articles and other secondary searches were also included. Tagging in HAWC categorized the useful articles into categories such as Health Assessment (66 references), Antibiotic intervention (31 references), Other Intervention (19 references), and so on. 


\section{A.1.2. Search Strings for $H$. pylori Searches}

Each search detailed below was limited to publication years from 2013 to 2017 and were combined with the RoC Cancer Filter.

Table A-2. The Full Search Strings for H. pylori Searches

\begin{tabular}{cl}
\hline Database & \multicolumn{1}{c}{ Search Terms } \\
\hline PubMed & (("Meta-Analysis"[pt] OR meta-analysis[tiab] OR Meta-Analyses[tiab] OR MetaAnalysis[tiab] OR \\
& metaanalyses[tiab]) OR ("Clinical Trial"[pt] OR Clinical-Trial*[tiab]) OR ("Public Health \\
& Surveillance"[mh] OR "Economics, Medical"[mh]) OR ("Markov Chains"[Mh] AND "Models, \\
& Statistical"[Mh] OR Markov-chain*[tiab]) OR ("Health Care Costs"[mh] OR "Cost-Benefit \\
& Analysis"[mh] OR cost-benefit[tiab]) OR "Review"[pt] OR "Treatment Outcome"[mh])) AND \\
& (("Controlled Before-After Studies"[Mh] OR "Interrupted Time Series Analysis"[Mh] OR "Early \\
& Medical Intervention"[Mh] OR Treatment*[tiab] OR intervention*[tiab] OR therapies[tiab] OR \\
& Therapy[tiab] OR prevent*[tiab])) AND (H-pylori[tiab] OR "Helicobacter pylori"[mh] OR \\
& Helicobacter-pylori[tiab]) \\
Web of & (TS=( "Meta-Analysis" OR "Meta-Analyses" OR "Metaanalysis" OR "metaanalyses" OR "Review" \\
Science & OR "Clinical Trial*" OR "Public Health Surveillance" OR "Medical Economics" OR "Markov \\
& Chain*" OR "Health Care Costs" OR "Cost-Benefit Analysis" OR cost-benefit OR "Review" OR \\
& "Treatment Outcome")) AND (TS=("Controlled Before-After Studies" OR "Interrupted Time Series \\
& Analysis" OR "Early Medical Intervention" OR Treatment* OR intervention* OR therapies OR \\
& Therapy OR prevent*)) AND (TS=(H-pylori OR "Helicobacter pylori")) \\
& ( TITLE-ABS-KEY ( "Meta-Analysis" OR "Meta-Analyses" OR "Metaanalysis" OR "metaanalyses" \\
Scopus & OR "Review" OR "Clinical Trial*" OR "Public Health Surveillance" OR "Medical Economics" OR \\
& "Markov Chain*" OR "Health Care Costs" OR "Cost-Benefit Analysis" OR cost-benefit OR \\
& "Review" OR "Treatment Outcome")) AND ( TITLE-ABS-KEY ("Controlled Before-After Studies" \\
& OR "Interrupted Time Series Analysis" OR "Early Medical Intervention" OR Treatment* OR \\
& intervention* OR therapies OR Therapy OR prevent*)) AND ( TITLE-ABS-KEY (H-pylori OR \\
& "Helicobacter pylori"))
\end{tabular}

\section{A.2. Identification of Cancer and Exposure Studies, Reviews, and Meta-analyses}

Literature on cancer and exposure studies, reviews, and meta-analyses related to H. pylori infection were identified through the use of narrowing terms for the relevant major topics within PubMed, and the resulting citations were saved directly into HAWC. HAWC was used to screen results and eliminate out-of-scope or duplicate references.

1. Prevalence searches in PubMed combined the MeSH term for H. pylori with the $\mathrm{MeSH}$ term for prevalence, limited to reviews published in the past 5 years, and 69 references were added to HAWC for evaluation.

2. Diagnosis searches used the H. pylori MeSH term and the diagnosis MeSH term, limited to review articles published since 01/01/2017, and 19 references were added to HAWC.

3. Finally, 368 recent reviews and meta-analyses for $H$. pylori were identified and added to HAWC for evaluation. 


\section{A.3. Updating the Literature Search}

The literature searches were last updated in PubMed, Scopus, and Web of Science on January 5, 2018. No additional publications were recommended by the peer reviewers. 


\section{Appendix B. Summary of Human Studies of Pancreatic and Colorectal Cancer}

\section{Table of Contents}

B.1. Pancreatic Cancer.

B-2

B.2. Colorectal Cancer...

B-2 
As mentioned in the Objective and Methods, NTP also reviewed recent meta-analyses, systematic reviews, and other reviews evaluating the association of $H$. pylori infection and other types of cancer, primarily pancreatic and colorectal cancer. A short summary of the updated findings on pancreatic and colorectal cancer is provided below.

\section{B.1. Pancreatic Cancer}

The 2009 IARC evaluation of $H$. pylori included four nested case-control studies (see IARC (2012), Table 2.21) and one case-control study of pancreatic cancer (Raderer et al. 1998). Since that time, five case-control studies (Gawin et al. 2012; Risch et al. 2014; Risch et al. 2010; Schulte et al. 2015; Shimoyama et al. 2010), one nested case-control study (Huang et al. 2017), two cohort studies (Chen et al. 2016; Hsu et al. 2014), and an update of a nested case-control study [Yu et al. (2013), which updated Stolzenberg-Solomon et al. (2001)] were identified. In addition, several recent meta-analyses were identified, of which the analysis by Schulte et al. (2015), which included 11 studies, was considered to be the most informative. This analysis reported meta ORs of $1.13(95 \% \mathrm{CI}=0.86$ to $1.50 ; 11$ studies $)$ for $H$. pylori infection and pancreatic cancer, $0.78(95 \% \mathrm{CI}=0.67$ to $0.91 ; 6$ studies $)$ for cytotoxin-associated gene A(CagA-) positive strains, and 1.30 (95\% CI = 1.02 to $1.65 ; 4$ studies) for CagA-negative strains. The meta-analysis did not include the recent large nested case-control study by Huang et al. (2017), which did not find an association with $H$. pylori infection, or sub-analyses for Cagnegative or -positive strains, nor the ESTHER cohort study, which found non-significant elevated risks for H. pylori infection with CagA-negative strains (Chen et al. 2016). NTP considered the database of studies inadequate to evaluate the association between $H$. pylori infection and pancreatic cancer and did not conduct a formal evaluation.

\section{B.2. Colorectal Cancer}

The 2009 IARC working group evaluation of $H$. pylori included 12 case-control studies (IARC (2012), Table 2.19) and two nested case-control studies of colorectal cancer (IARC (2012), Table 2.18). Since that time, several meta-analyses and at least ten studies on colorectal cancer have been published. Recent meta-analyses that were specific for colorectal cancer (i.e., did not include colon adenoma) reported modestly increased colorectal cancer risks ( $20 \%$ to $40 \%)$ with H. pylori infection [e.g., Rokkas et al. (2013); Wang et al. (2014); Wu et al. (2013)]; however, heterogeneity was observed, and many studies included in the analyses were small, crosssectional, hospital-based case-control studies, or did not adjust for potential confounding factors. The most informative studies were four large population-based case-control studies (Fernández de Larrea-Baz et al. 2017; Machida-Montani et al. 2007; Zhang et al. 2012; Zumkeller et al. 2007), three nested case-control studies (Blase et al. 2016; Epplein et al. 2013; Limburg et al. 2002), and a cohort study (Chen et al. 2016) that reported adjusted risk estimates. Findings among these studies were inconsistent. Two population-based case-control studies in Germany (Zhang et al. 2012; Zumkeller et al. 2007) found positive associations with $H$. pylori infection. In addition, two nested case-control studies, an analysis within the U.S. Southern Community Cohort Study (Epplein et al. 2013), and an analysis of elderly Caucasians in the CPS-II Nutrition Cohort (Blase et al. 2016) reported positive associations with some specific H. pylori antigens but not $H$. pylori infection in general. Few studies have looked at specific antigens, and the results were inconsistent across studies. The other informative studies did not find an association 
with H. pylori infection or specific antigens (Chen et al. 2016; Fernández de Larrea-Baz et al. 2017; Limburg et al. 2002; Machida-Montani et al. 2007). The evidence for an association between $H$. pylori infection and colon adenoma or polyps may be stronger, but adenoma is outside the scope of a cancer hazard evaluation. Based on this initial review, NTP did not conduct a formal evaluation of colorectal cancer. 


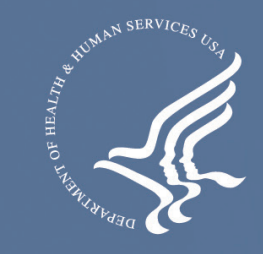

\section{National Toxicology Program}

National Institute of Environmental Health Sciences

National Institutes of Health

P.O. Box 12233, MD K2-05

Durham, NC 27709

Tel: 984-287-3211

ntpwebrequest@niehs.nih.gov

https://ntp.niehs.nih.gov 